\title{
GABA Shapes a Topographic Organization of Response Latency in the Mustache Bat's Inferior Colliculus
}

\author{
Thomas J. Park and George D. Pollak \\ Department of Zoology, University of Texas at Austin, Austin, Texas 78712
}

Many neurons in the auditory forebrain of the mustache bat act as coincidence detectors for signals separated in time by up to 20 msec. Differences in path lengths cannot adequately explain how the nervous system delays one signal relative to the other to such a large degree. Several researchers have proposed that an inhibitory mechanism might account for long delays, but it has not been known where these delays are created. Previous studies, using a variety of mammals, have reported that the inferior colliculus contains some cells with much longer latencies than those of cells in lower auditory centers, suggesting that the inferior colliculus might be the site where long delays are generated.

We characterized the latencies of cells in the $60 \mathrm{kHz}$ contour of the mustache bat inferior colliculus and examined how GABAergic inhibition affected the latencies of those cells. Evaluations of the influence of GABA were made by documenting changes in response latency that occurred when GABAergic inputs were reversibly blocked by iontophoretic application of the GABA $_{A}$ antagonist bicuculline. Prior to bicuculline application, latencies varied over a wide range among the population of cells and we observed a pattern of latency changes with dorsoventral location. The pattern was that the population of neurons in the dorsal regions of the inferior colliculus had a wide range of latencies while the population in more ventral regions had progressively narrower latency ranges. Thus, while some cells at each depth had comparably short latencies, the average latency of the population at a given depth was long in the dorsal inferior colliculus and became progressively shorter ventrally. The same characteristic distribution of latencies and pattern of latency changes with depth were observed for cells that had different aural preferences, different rateintensity functions, and different discharge patterns, suggesting that latency is an important organizational feature of the inferior colliculus.

Bicuculline substantially shortened latency in about half of the cells studied, and it dramatically altered the pattern of latency changes with depth. These results suggest that

\footnotetext{
Received Jan. 19, 1993; revised June 3, 1993; accepted June 7, 1993.

We thank Carl Resler for designing and implementing the electronics and computer programs, without which this study could not have been conducted. We also thank Don Caspary for instructing us in the techniques of microiontophoresis. We thank Mike Ferrarri, Carl Resler, Lenny Yang, and two anonymous reviewers for their thoughtful comments on the manuscript. We thank the Natural Resources Conservation Department of Jamaica for assistance in collecting the bats. This work was supported by NIH Grants DC 20068 (G.D.P.) and NS 07281 (T.J.P.).

Correspondence should be addressed to Dr. Thomas J. Park at the above address.

Copyright (c) 1993 Society for Neuroscience $0270-6474 / 93 / 135172-16 \$ 05.00 / 0$
}

GABA normally lengthens response latencies and creates a dorsoventral grading of delays in the inferior colliculus. This wide range of latencies could provide the large latency differences necessary for the coincidence detectors in the medial geniculate body tuned to signals separated by up to 20 msec.

IKey words: GABA, latency, delay mechanism, inferior colliculus, mustache bat, inhibition]

Latency has proven to be an important feature for both the binaural and monaural processing of acoustic information. Differences in latency from the two ears underlie coincidence detection in the medial superior olive (Goldberg and Brown, 1969; Yin and Chan, 1990) and the avian homolog, the nucleus laminaris (Parks and Rubel, 1975; Young and Rubel, 1983; Sullivan and Konishi, 1986; Carr and Konishi, 1988, 1990; Overholt et al., 1992), and thus the coding of interaural phase disparities of low-frequency signals. It also is thought to form an important component for the binaural processing of high frequencies, as illustrated by the ability of the nervous system to trade time for intensity (Brugge et al., 1969; Caird and Klinke, 1983; Yin et al., 1985; Pollak, 1988). With regard to monaural processing, the importance of latency differences is clearly expressed in the delay tuned neurons of echolocating bats (e.g., O'Neill and Suga, 1982; Sullivan, 1982a,b; Olsen and Suga, 1991b; Wong et al., 1992). These neurons are characterized by responding best or only when two signals, each with a different frequency, are presented with a temporal interval to which the unit is specifically tuned. In the medial geniculate body of the musatche bat, the delay tuning can be evoked with two tone bursts or with two brief FM stimuli (Olsen and Suga, 1991b). The two acoustic signals are designed to simulate the emitted pulses and echoes that the bat normally hears from targets at different distances, where the first signal mimics the bat's emitted pulse while the second signal mimics the echo reflected from a target located at a particular distance. Studies have shown that delay-tuned neurons, like neurons in the medial superior olive, are coincidence detectors and discharge most vigorously when the excitation evoked by the two signals arrives simultaneously at the delaytuned neuron (Sullivan, 1982b; Olsen and Suga, 1991b). Thus, the response evoked by the first signal, which is presented 1$20 \mathrm{msec}$ before the second signal, must have a longer latency than the response evoked by the second signal for coincidence to occur. In addition, the latency differences must be different among the population of neurons to produce the variety of delayed tuned values expressed by these cells. In mustache bats, these neurons are initially created in the medial geniculate and are prominent in both the medial geniculate body and in a 
number of cortical regions. In both the medial geniclate body and the cortex, the delay-tuned values are arranged systematically and this arrangement is thought to be a map of target range or distance (Suga and O'Neill, 1979; O'Neill and Suga, 1982; Olsen and Suga, 1991b).

A great deal of attention has been directed at the anatomical and physiological substrates that could produce the delays necessary for both monaural and binaural processing. Jeffress (1948) first proposed that the anatomical basis for coincidence detection of binaural signals is due to the orderly arrangement of differences in path length from the two ears. Anatomical studies of the avian auditory system have shown the architectural basis for the Jeffress's delay lines (Young and Rubel, 1983; Carr and Konishi, 1988, 1990), and a recent physiological study provides an additional demonstration that the system functions as coincidence detectors in a fashion predicted by Jeffress (Overholt et al., 1992).

While the Jeffress type of delay lines are elegantly suited for processing interaural delays of up to a few hundred microseconds, they are inadequate to account for the delay tuning of the "target range neurons" in bats. Not only is the brain of the bat very small, but the delays required by these cells range from about 1 to $20 \mathrm{msec}$. These delays are too large to explain on the basis of path length differences resulting from multiple synaptic delays or axonal lengths. Even the most generous assumptions for path lengths and differences in conduction velocity between fibers can at best account for latency differences on the order of 2-3 msec. In view of the inadequacy of a path length explanation, several investigators have proposed that the latency differences evoked by two signals probably are a result of inhibition (Suga, 1990; Olsen and Suga, 1991b). Specifically, that the excitatory latency at the medial geniculate body or the cortex evoked by the first signal, or simulated pulse, is lengthened by inhibition somewhere along the auditory pathway, whereas the excitatory latency evoked by the second signal, or echo, is less affected by inhibition or not affected at all. Moreover, since there is an orderly arrangement of delay tuning in the medial geniculate body, they postulate that there may be a latency map of some sort in an auditory nucleus below the medial geniculate. In previous studies, Suga and his colleagues found that latencies in the mustache bat inferior colliculus were topographically organized but they varied over only about $7 \mathrm{msec}$ (Kuwabara and Suga, 1988; Hattori and Suga, 1989). These findings led Suga (1990) to propose that the map of delay lines is partially assembled in the inferior colliculus, but is fully formed only in the medial geniculate body.

Over the past several years we have been evaluating the response properties of single units in the hypertrophied $60 \mathrm{kHz}$ isofrequency contour of the mustache bat's inferior colliculus (e.g., Zook et al., 1985; Wenstrup et al., 1986, 1988; Ross et al., 1988; Ross and Pollak, 1989; Park and Pollak, 1993; Pollak and Park, 1993). Our assumption is that since the unit module of the auditory system is the isofrequency contour, the functional organization of the $60 \mathrm{kHz}$ contour and the response properties of its neurons are general features that are also present in the other, less prominently represented contours of the inferior colliculus. During the course of monitoring single-unit activity from the mustache bat's inferior colliculus, we observed a wide range of latencies in the $60 \mathrm{kHz}$ contour that were distributed in a characteristic fashion. Here we report on these features and on the role that GABAergic inhibition plays in modifying the latencies of collicular units, and hence its role in creating delay lines that may be important for the generation of delay-tuned cells in the medial geniculate.

\section{Materials and Methods}

Surgical procedures. Thirty Jamaican mustache bats, Pteronotus parnellii parnellii, were experimental subjects. Prior to surgery, animals were anesthetized with methoxyflurane inhalation (Metofane, PitmanMoore, Inc.) and $10 \mathrm{mg} / \mathrm{kg}$ sodium pentobarbital injected intraperitoneally. The hair on the bat's head was removed with a depilatory and the head secured in a head holder with a bite bar. The muscles and skin overlying the skull were reflected and lidocaine (Elkins-Sinn, Inc.) was applied topically to all open wounds. The surface of the skull was cleared of tissue, and a ground electrode was placed just beneath the skull over the cerebellum. A layer of small glass beads and dental acrylic was placed on the surface of the skull to secure the ground electrode and to serve as a foundation layer to be used later for fixing the head in the stereotaxic apparatus. A small hole (approximately $0.5-1.0 \mathrm{~mm}$ diameter) was then drilled over the inferior colliculus on one side using landmarks visible through the skull for orientation.

The bat was transferred to a heated $\left(27-30^{\circ} \mathrm{C}\right)$, sound-attenuated room, where it was placed in a restraining apparatus attached to a custommade stereotaxic instrument (Schuller et al., 1986). A small metal rod was cemented to the foundation layer on the skull and then attached to a bar mounted on the stereotaxic instrument to ensure uniform positioning of the head. Recordings were begun after the bat was awake. Intramuscular injections of the neuroleptic Innovar-Vet $(0.01 \mathrm{ml} / \mathrm{gm}$ body weight; Pitman-Moore, Inc.) were given if the bat appeared in discomfort.

Recording electrodes. Glass micropipettes were used to record from single units. Single-barrel micropipettes were pulled to a tip diameter less than $1 \mu \mathrm{m}$ and filled with buffered $1 \mathrm{M} \mathrm{NaCl}$ with $2 \%$ fast green (pH 7.4). Electrode impedances ranged from 5 to $20 \mathrm{M} \Omega$. The fast green was used to enhance the visibility of the electrode for placement in the small hole made in the skull. The recording barrel of the microelectrode was connected by a silver-silver chloride wire to the head stage of a Dagan AC amplifier (model 2400). Electrode penetrationss were made vertically through the exposed dorsal surface of the inferior colliculus and electrode placement was based on surface landmarks viewed with an operating microscope. Subsequently, the electrode was advanced from outside of the experimental chamber with a piezoelectric microdrive (Burleigh 712IW). Units were recorded at depths below the surface ranging from 250 to $1500 \mu \mathrm{m}$.

Fifteen of the bats were used to test the effects of blocking GABA $_{A}$ receptors with iontophoretic application of bicuculline methiodide (Sigma) (Cooper et al., 1982; Borman, 1988). For these experiments, the single-barrel recording pipette was attached to a five-barrel electrode used for drug delivery to construct a "piggyback" multibarrel electrode, as described by Havey and Caspary (1980). The five-barrel electrode (H-configuration, Omega dot, Glass Company of America) was pulled and the tips were broken back under microscopic observation so that the tip diameter of the multibarrel array was $10-15 \mu \mathrm{m}$. The singlebarrel micropipette was positioned at an angle of approximately $20^{\circ}$ to the five-barrel pipette and glued with cyanoacrylate so that the tip of the single-barrcl pipette protruded about $10 \mu \mathrm{m}$ in front of the broken tips of the five-barrel pipette. One of the multibarrels was used to balance current. This balancing (sum channel) barrel was also filled with buffered $1 \mathrm{M} \mathrm{NaCl}$ and $2 \%$ fast green $(\mathrm{pH} 7.4)$. One ejection barrel was filled with GABA (500 mm, pH 3.5-4.0; Sigma) and another with bicuculline methiodide ( $10 \mathrm{~mm}$, pH 3.0; Sigma). Another barrel was filled with the drug delivery vehicle $(0.16 \mathrm{M} \mathrm{NaCl}, \mathrm{pH} 3.5)$. All solutions were prepared just prior to each experiment and the electrodes were filled immediately before use. Bicuculline was mixed with $0.16 \mathrm{M} \mathrm{NaCl}$ in which the $\mathrm{pH}$ was adjusted to 3.0 by titration with $0.10 \mathrm{M} \mathrm{HCl}$. GABA was mixed in distilled water in which the $\mathrm{pH}$ was adjusted to $3.5-4.0$ with $0.10 \mathrm{M}$ $\mathrm{HCl}$. The drug barrels and balancing barrel were connected via silversilver chloride wires to a six-channel microiontophoresis constant current generator (Medical Systems Neurophore BH-2) that was used to gencrate and monitor iontophoretic currents. The sum channcl was employed to balance current in the drug barrels and reduce current effects.

Acoustic stimuli, data acquisition, and processing. A custom-made electronic switch shaped sine waves from a Wavetek oscillator (model 136) into $20 \mathrm{msec}$ tone bursts having $0.5 \mathrm{msec}$ rise-fall times. During data acquisition, the sound intensity of the bursts was selected pseu- 
dorandomly by a Macintosh IIci computer that controlled an electronic attenuator (Wilsonics, model PATT) via a 24 bit digital interface (Metrabyte MAC PIO-24) and a Digital Distributor (Restek model 99). The output of the attenuator went to two loudspeakers (Panasonic ultrasonic ceramic loudspeaker, EFR-OTB40K2). The loudspeakers were fitted with plastic probe tubes $(5 \mathrm{~mm}$ diameter) that were placed in the funnels of each pinna. Maximum sound intensity was $85 \mathrm{~dB}$ SPL measured at $0.5 \mathrm{~cm}$ from the opening of the probe tubes. Sound pressure and the frequency response of the loudspeakers were measured with a $1 / 4$ inch Brüel and Kjaer microphone (type 4135) and a Brüel and Kjaer measuring amplifier (type 2608). Each loudspeaker showed less than $\pm 3 \mathrm{~dB}$ variability for the frequency range used $(55-65 \mathrm{kHz})$ and intensities between the loudspeakers did not vary more than $\pm 2 \mathrm{~dB}$ at any of those frequencies. Tone bursts were presented at a rate of 4 per second. Acoustic isolation between the ears was $40-50 \mathrm{~dB}$ and was determined empirically by testing monaural units during the course of the experiments. Monaural units were responsive to sound at the contralateral ear and were unaffected by ipsilateral sounds up to $40 \mathrm{~dB}$ higher in intensity than the threshold at the contralateral ear. After the threshold for the contralateral ear was determined, that loudspeaker was turned off and the ipsilateral speaker was activated. The threshold difference in decibels between the ipsilateral and contralaterl loudspeakers was taken as a measure of acoustic isolation.

Only well-isolated spikes with a signal-to-noise ratio of at least 8 were studied. Spikes were fed to a window discriminator and the output of the discriminator was fed to the computer. When a unit was encountered, its characteristic frequency and absolute threshold were audiovisually determined in order to set stimulus parameters subsequently controlled by the computer. The characteristic frequency was defined as the frequency that elicited responses at the lowest sound intensity to which the unit was sensitive. Binaural stimuli were then presented to determine whether the unit was monaural (EO) or binaural, and if it was binaural, whether it was excitatory/inhibitory (EI) or excitatory/ excitatory (EE). Units were classified as excitatory/inhibitory if sound at the inhibitory ear suppressed the responses evoked by the contralateral ear by at least $50 \%$. For each excitatory/inhibitory unit, sounds at various intensities were presented monaurally to the ipsilateral (inhibitory) ear and the influence of this stimulation was monitored audiovisually. Only cells in which monaural stimulation of the ipsilateral ear did not evoke discharges were classified as excitatory/inhibitory. Excitatory/ excitatory binaural cells were excited by monaural stimulation of each car.

Poststimulus time (PST) histograms, raster displays, and rate-intensity functions were generated for each unit. Responses were evoked with characteristic frequency tone bursts presented to the contralateral ear at intensities from $10 \mathrm{~dB}$ below to $40 \mathrm{~dB}$ above threshold. Each intensity was presented 20 times, and the order of presentation was varied pseudorandomly. Data were displayed on the computer screen for inspection during the experiments and stored on hard disk for later analysis. The computer calculated the median latency of the first spike evoked by the presentation of 20 characteristic frequency tone bursts. The resolution of measurement for each first spike was $0.1 \mathrm{msec}$. For five cells, spontaneous activity was present when the loudspeakers were activated and when they were inactivated for the predrug and/or the bicuculline conditions. These cells were not used in the present study because the spontaneous activity interfered with an accurate assessment of response latency.

The temporal discharge pattern of each unit was classified as either sustained or phasic. Sustained units discharged throughout the duration of the tone burst while phasic units discharged only one or a few spikes at the beginning of each tone burst. Units that fired to the onset and the offset of the stimulus, and were silent during the intervening period which corresponded to the tone burst duration, were also classified as phasic. The discharge patterns of 30 cells were not classified because their discharge patterns did not clearly fit into either of the two categories described above.

Rate-intensity functions were classified as either monotonic or nonmonotonic. Cells with monotonic rate-intensity functions exhibited increasing discharge rates with intensity. Some monotonic functions became saturated while others continued to increase and thus did not saturate. In units with nonmonotonic rate-intensity functions, the discharge rate at first increased and reached a maximum at some intensity but with additional intensity increments the discharge rate declined by at least $25 \%$, and usually more, from the maximum rate.

For units receiving drug application, responses were recorded before and during drug application. If contact with the unit was maintained after these data were obtained, responses were also recorded after drug application until the unit displayed the same properties that were evoked before drug application. When a drug was not being applied, a retention current of $15 \mathrm{nA}$ (electrode negative) was applied to each drug barrel to prevent leakage of drugs. Drugs were iontophoretically applied by turning off the negative retention current and switching to a positive ejection current.

Dosages of bicuculline were determined from the drug's affect on maximum spike count (bicuculline increased the firing rate of virtually every cell tested). A low ( $5 \mathrm{nA}$ ) ejection current was initially used. Rateintensity functions were obtained until the shape of the function and the maximum spike-count stabilized. The current was then increased and the procedure repeated. The currents most frequently employed ranged from 5 to $20 \mathrm{nA}$. However, higher currents were sometimes employed with neurons whose firing rates continued to increase with ejection currents greater than $20 \mathrm{nA}$. Electrode resistance was monitored continuously and only cases in which resistance did not change throughout drug application are reported. The applied voltage that maintained the constant ejection currents was also monitored and was within the range reported by Purves (1981) for a linear relation between drug release and ejection current.

To assure that changes in response features were due to bicuculline and not to the applied current, responses were obtained when drugs were not ejected but a current equal to the bicuculline ejection current was passed through the balancing barrel. Those responses were compared to the predrug and bicuculline-induced responses. To control for any effects that the low $\mathrm{pH}$ of the vehicle might cause, current was passed through the vehicle alone. The responses of two cells appeared to be influenced by current artifacts, so the data for those cells were discarded and the electrodes were immediately replaced. An account of the general effects of GABA, bicuculline, and vehicle alone on cells in the mustache bat's inferior colliculus has been presented elsewhere (Pollak and Park, 1993).

After collecting data with bicuculline, the ejection current was switched off and the cell was allowed to recover. Recovery was complete when the shape of the rate-intensity function and the maximum spike count returned to predrug form. Recovery from bicuculline occurred over periods ranging from a few minutes up to $30 \mathrm{~min}$, depending on the previous ejection current and the length of time bicuculline had been applied.

\section{Results}

This report is based on the latencies of 302 units recorded from the $60 \mathrm{kHz}$ contour in the central nucleus of the inferior colliculus. Of these cells, 142 were studied both before and while GABAergic inhibition was blocked by the iontophoretic application of bicuculline. Each unit was categorized according to it aural preference, whether it was monaural or binaural. If binaural, we determined whether it received excitatory inputs from one ear and inhibition inputs from the other (EI), or excitatory inputs from both ears (EE). Units were further categorized on the basis of their rate-intensity function, which was either monotonic or nonmonotonic, and from their temporal discharge pattern, which was either phasic or sustained.

The major aim of this study was to assess the response latencies of collicular neurons and some of the mechanisms that contribute to latency. Below we first describe the distribution of first spike latencies and examine how latency changed when intensity was increased from 10 to $20 \mathrm{~dB}$ above threshold and then from 20 to $30 \mathrm{~dB}$ above threshold. Latencies to higher intensities are not shown because most of the nonmonotonic cells responded very weakly or not at all at higher intensities, and thus their latencies were difficult to measure. We compare the distribution of latencies among cells that had different rateintensity functions, temporal discharge patterns, and aural response properties. We then describe how latencies varied with depth in the $60 \mathrm{kHz}$ contour. Finally, we describe how blocking 
GABAergic inputs with the $\mathrm{GABA}_{\mathrm{A}}$ antagonist bicuculline affected latencies.

\section{Distribution of latencies}

The population of $60 \mathrm{kHz}$ neurons had latencies that ranged from a minimum of $5 \mathrm{msec}$ to a maximum of $45 \mathrm{msec}$, but the majority of neurons (about $85 \%$ ) had latencies that clustered between 8 and $20 \mathrm{msec}$. These features are illustrated in Figure 1, which shows the distribution of latencies evoked at 10,20, and $30 \mathrm{~dB}$ above threshold. Although the shapes of the latency distributions obtained at each of the three intensities were similar, some significant changes occurred with intensity. As intensity was increased from 10 to $20 \mathrm{~dB}$ above threshold, there was a shift in the population toward shorter latencies. At $20 \mathrm{~dB}$ above threshold, the number of units whose latencies clustered between 8 and $20 \mathrm{msec}$ was considerably larger than at $10 \mathrm{~dB}$. These shifts were reflected in the decrease in average latency: at $10 \mathrm{~dB}$ above threshold the average latency of the population was $14.7 \mathrm{msec}$, while the average latency at $20 \mathrm{~dB}$ above threshold declined to $13.0 \mathrm{msec}$. In contrast, when intensity was further increased, from 20 to $30 \mathrm{~dB}$ above threshold, the average latency remained constant at $13.0 \mathrm{msec}$. An ANOVA comparing the latencies at 10,20, and $30 \mathrm{~dB}$ above threshold showed a significant difference among the distributions $(F=8.122, \mathrm{df}=$ $2,903, p<0.01)$ due to the differences in latencies between 10 and $20 \mathrm{~dB}$ and between 10 and $30 \mathrm{~dB}$. There was no difference between 20 and $30 \mathrm{~dB}$ above threshold.

\section{Latency distributions of neurons with different response features}

We also divided the neurons into the various response types described previously and plotted their latency distributions. Figure 2 shows the latency distributions evoked at $20 \mathrm{~dB}$ above threshold for cells with monotonic versus nonmonotonic rateintensity functions, for cells with sustained versus phasic discharge patterns, and for cells with monaural and binaural response properties. In general, the latency distributions were very similar in that each had a wide range of latencies and most latencies in each distribution clustered between 8 and $20 \mathrm{msec}$. Although not shown, the latency distributions of neurons with the different response properties obtained with tone bursts 10 $\mathrm{dB}$ and $30 \mathrm{~dB}$ above threshold were also similar. In all of the distributions, the average latencies of the populations shortened when intensity was increased from 10 to $20 \mathrm{~dB}$ above threshold, but there were no further changes in average latency when intensity was increased to $30 \mathrm{~dB}$ above threshold.

There were two minor but significant differences among the latency distributions. These concerned the latency distributions among the aural types and between phasic compared to sustained neurons. Turning first to the latency distributions among the aural types, at each intensity the average latency of the EI cells was longer than the average latency of the EE and monaural cells $(F=3.8, \mathrm{df}=2,299, p<0.05$, two-way ANOVA). For example, at $10 \mathrm{~dB}$ above threshold, the average latency of the EI cells was $16.1 \mathrm{msec}$ while that of the EE cells was $14.1 \mathrm{msec}$ and that of the EO cells was $13.2 \mathrm{msec}$ (Table 1). At 20 and 30 $\mathrm{dB}$ above threshold, the average latencies of the EI cells were also longer than the two other types, although the differences were slightly less than at $10 \mathrm{~dB}$. The reasons for these differences are unclear.

With regard to the sustained and phasic cells, for any given
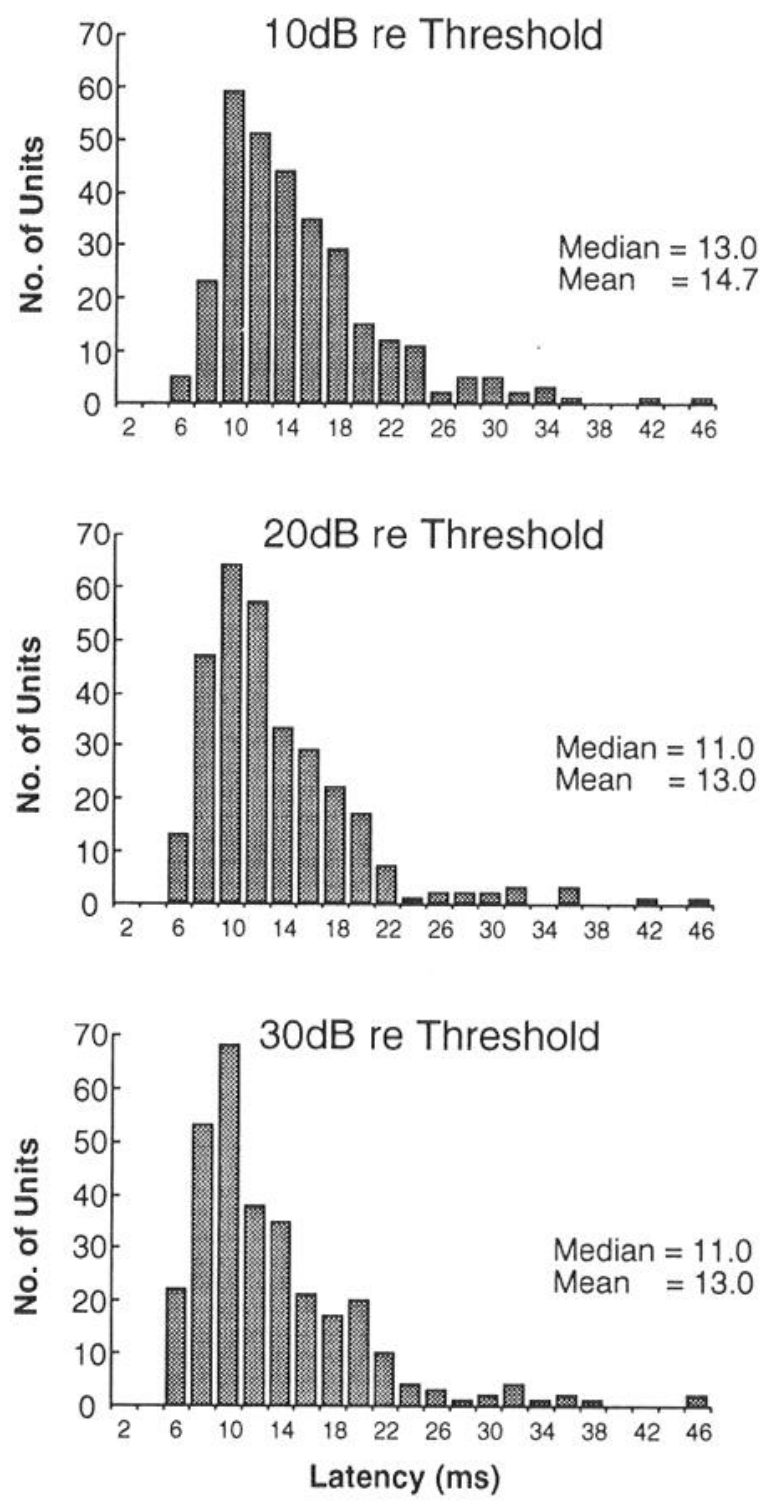

Figure 1. Histograms showing the distributions of latency for 302 units at 10,20 , and $30 \mathrm{~dB}$ above threshold. The median and mean latency for each distribution are shown on the right.

intensity the average latency of the sustained cells was slightly longer than the average latency of the phasic cells $(F=5.6$, df $=1,270, p<0.05$, two-way ANOVA). At $10 \mathrm{~dB}$ above threshold, the average latency of the sustained cells was $16.6 \mathrm{msec}$ while that of the phasic cells was $14.2 \mathrm{msec}$, a difference of 2.4 msec (Table 1). At $20 \mathrm{~dB}$ above threshold, the difference was $1.5 \mathrm{msec}$, and at $30 \mathrm{~dB}$ above threshold the difference was 1.4 msec. The reason for the difference in average latency between the sustained and phasic units was that the latency to first spike was more variable from stimulus to stimulus for the sustained units than for the phasic units. Cells of both response types discharged to some stimulus presentations with relatively short latencies and to others with relatively long latencies. Thus, with tonic units the latencies were spread over much of the duration of the tone burst, whereas with phasic units the latencies were spread over a shorter period following the onset of the tone burst. In other words, the latencies of the sustained cells were frequently much longer than those of the phasic cells, which 
A

Tonicity
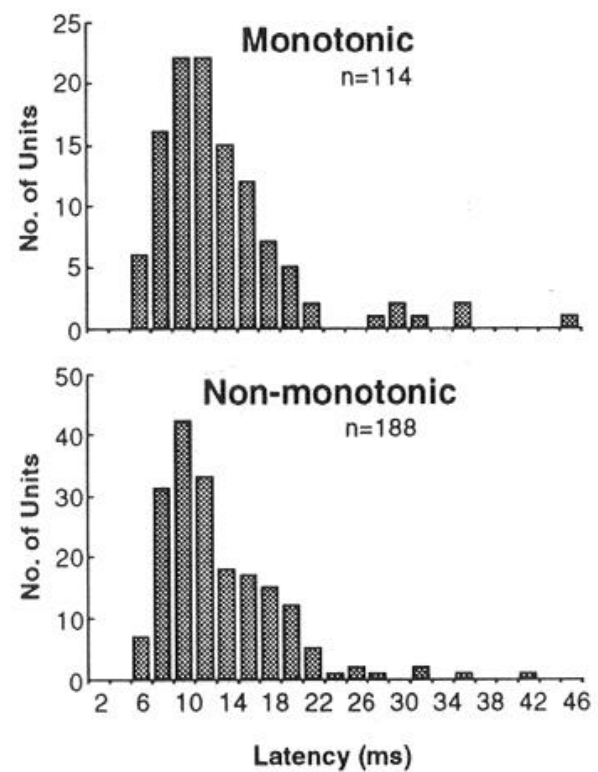

B

Resp. Pattern
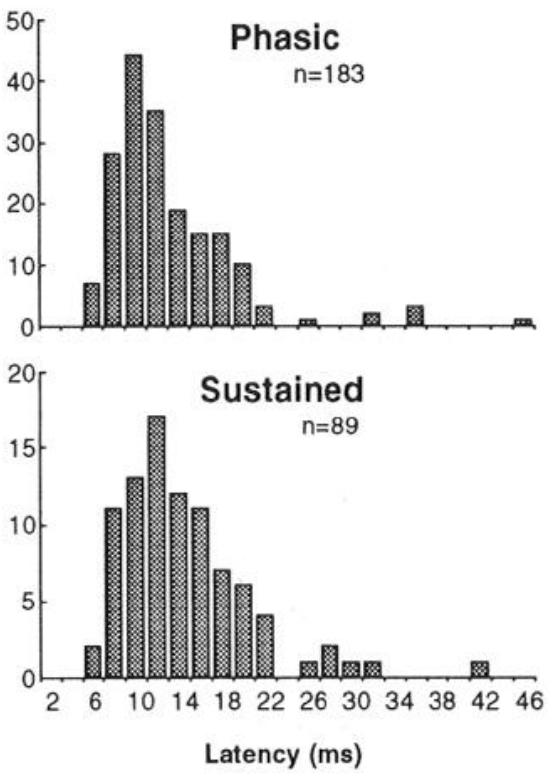

Latency (ms)
Aurality

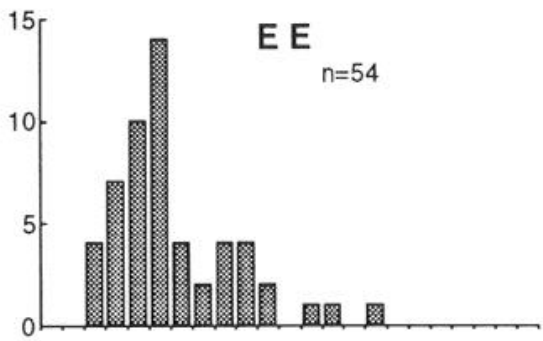

E I

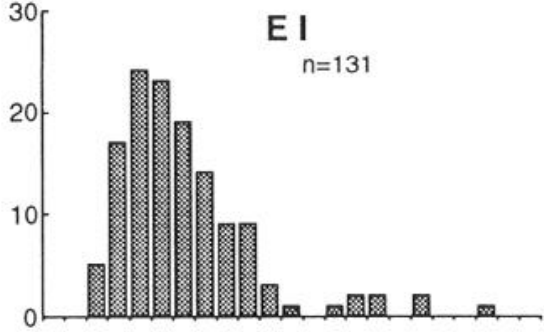

E O

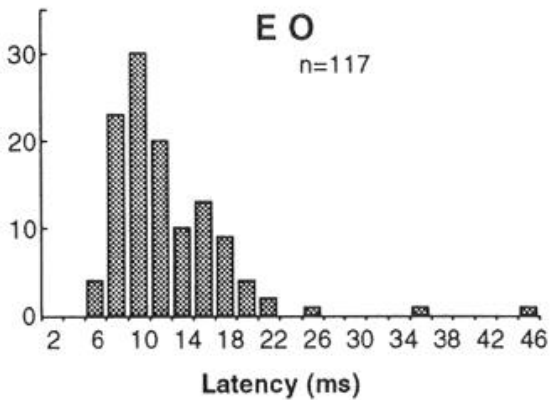

Figure 2. Distributions of latencies for cells with different response types. A, Distributions for cells with monotonic and nonmonotonic rateintensity functions. $B$, Distributions for cells with phasic and sustained response patterns. $C$, Distributions for cells with different binaural and monaural properties.

increased the median latencies of the sustained cells over that of the phasic cells. These features are illustrated in Figure 3, left side, by raster displays of discharge latencies for a phasic and a sustained neuron.

\section{Pattern of latencies along the dorsoventral axis of the $60 \mathrm{kHz}$ contour}

There was a pattern to the distribution of latencies within the $60 \mathrm{kHz}$ contour. The pattern was that the population of neurons in the dorsal regions of the inferior colliculus had a wide range of latencies, while the population in more ventral regions had progressively narrower latency ranges. Thus, while some cells at each depth had comparably short latencies, the average latency of the population at a given depth was long in the dorsal inferior colliculus and became progressively shorter ventrally. These features are shown in Figure 4 for latencies obtained at 10,20 , and $30 \mathrm{~dB}$ above threshold. The latency values at $20 \mathrm{~dB}$ above threshold (Fig. 4, middle panel) illustrate the quantitative changes in the range and average latency with depth. The average latency in the dorsal part of the inferior colliculus, extending from 200 to $600 \mu \mathrm{m}$ from the surface, was $14.8 \mathrm{msec}$. The average latency decreased to $12.0 \mathrm{msec}$ at midlevels of the in-

\begin{tabular}{|c|c|c|c|c|c|c|c|c|}
\hline \multirow{3}{*}{$\begin{array}{l}\text { Intensity } \\
\text { re } \\
\text { threshold } \\
\end{array}$} & \multirow[b]{3}{*}{ Population } & \multicolumn{2}{|c|}{ Rate-intensity type } & \multirow{2}{*}{\multicolumn{2}{|c|}{ Discharge type }} & \multirow{2}{*}{\multicolumn{3}{|c|}{ Aural type }} \\
\hline & & \multirow{2}{*}{$\begin{array}{l}\text { Mono- } \\
\text { tonic }\end{array}$} & \multirow{2}{*}{$\begin{array}{l}\text { Non- } \\
\text { monotonic }\end{array}$} & & & & & \\
\hline & & & & Phasic & Sustained & $\mathrm{EO}$ & EI & $\mathrm{EE}$ \\
\hline$(n)$ & $(302)$ & (114) & $(188)$ & (183) & (89) & (54) & (133) & (117) \\
\hline $10 \mathrm{~dB}$ & 14.7 & 15.4 & 14.2 & 14.2 & 16.6 & 13.2 & 16.1 & 14.1 \\
\hline $20 \mathrm{~dB}$ & 13.0 & 13.2 & 12.9 & 12.8 & 14.3 & 12.2 & 13.7 & 12.8 \\
\hline $30 \mathrm{~dB}$ & 13.0 & 12.7 & 13.1 & 12.7 & 14.1 & 12.3 & 13.7 & 12.6 \\
\hline
\end{tabular}

Results are in msec; numbers in parentheses are number of units. 


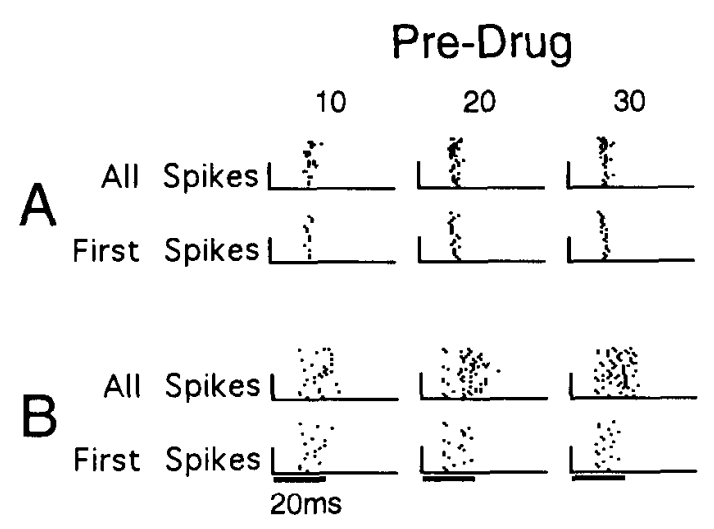

ferior colliculus, from about 600 to $1000 \mu \mathrm{m}$, and the average latency decreased further to about $9.8 \mathrm{msec}$ in more ventral regions, from 1000 to $1400 \mu \mathrm{m}$. In addition, the range of latencies changed markedly with depth, with a broad distribution of latencies dorsally and a much narrower range of latencies ventrally. The latencies recorded dorsally, within $200-600 \mu \mathrm{m}$ of the collicular surface, ranged from 5 to $45 \mathrm{msec}$, the latencies at midlevels ranged from 5 to $41 \mathrm{msec}$, while the latencies at depths from 1000 to $1400 \mu \mathrm{m}$ ranged from 5 to $15 \mathrm{msec}$. Thus, long-latency cells were found dorsally whereas short-latency cells were found at all depths.

Pattern of latency changes with depth of monaural, EI, and $E E$ neurons. EO neurons and the two major binaural types, the EI and EE ncurons, are regionally segrcgated within subregions of the $60 \mathrm{kHz}$ contour (Wenstrup et al., 1986; Ross and Pollak, 1989). In any subregion of the contour, neurons having one aural type predominate. We showed previously that the range of latencies and the form of the latency distribution in each of the aural subregions were similar to each other and were similar to the distribution of the latencies for the entire population of neurons independent of aural type. Therefore, when latency as a function of depth was plotted for EO, EI, and EE neurons, it was not surprising that each aural type had the same pattern as was found for the population of pooled neurons. As shown in Figure $5 C$, a wide distribution of latencies and a relatively high average latency were found dorsally for each of the aural types, while the more ventral neurons of each type had a narrower range of latencies and shorter average latencies. These patterns of latency with depth illustrated at $20 \mathrm{~dB}$ above threshold in Figure $5 C$ were also observed at 10 and $30 \mathrm{~dB}$ above threshold for $\mathrm{EO}, \mathrm{EI}$, and $\mathrm{EE}$ units. Table 2 presents the average latency and range for each aural type and intensity.

Pattern of latency changes with depth for neurons with other response properties. Neurons that had monotonic and nonmonotonic rate-intensity functions as well as neurons that had phasic and sustained discharge patterns were found at all dorsoventral levels of the $60 \mathrm{kHz}$ contour. The neuronal populations that displayed each of these response features also expressed a common pattern of latency changes with depth. This is illustrated in Figure $5 A$, which shows that the decrease in average latency and latency range with depth were both similar for ncurons with monotonic rate-intensity functions and for neurons with nonmonotonic rate-intensity functions. Furthermore, comparable patterns of latency changes with depth were found when the latencies of these neurons were measured at 10 and $30 \mathrm{~dB}$ above threshold (Table 2). This pattern was also observed for neurons that had a sustained discharge pattern to tone bursts and for
Figure 3. Raster displays showing the responses of two units. In each graph, the $x$-axis is time beginning with the stimulus onset and the $y$-axis shows the discharges to each of 20 stimulus repetitions. Each dot represents a single discharge. $A$, Raster displays from a phasic unit beforc and during bicuculline application. For predrug data (left), the upper three graphs show the entire discharge train elicited by the stimuli at 10,20 , and $30 \mathrm{~dB}$ above threshold; the lower three graphs show only the first spike to each stimulus presentation. $B$, Raster displays from a sustained unit.
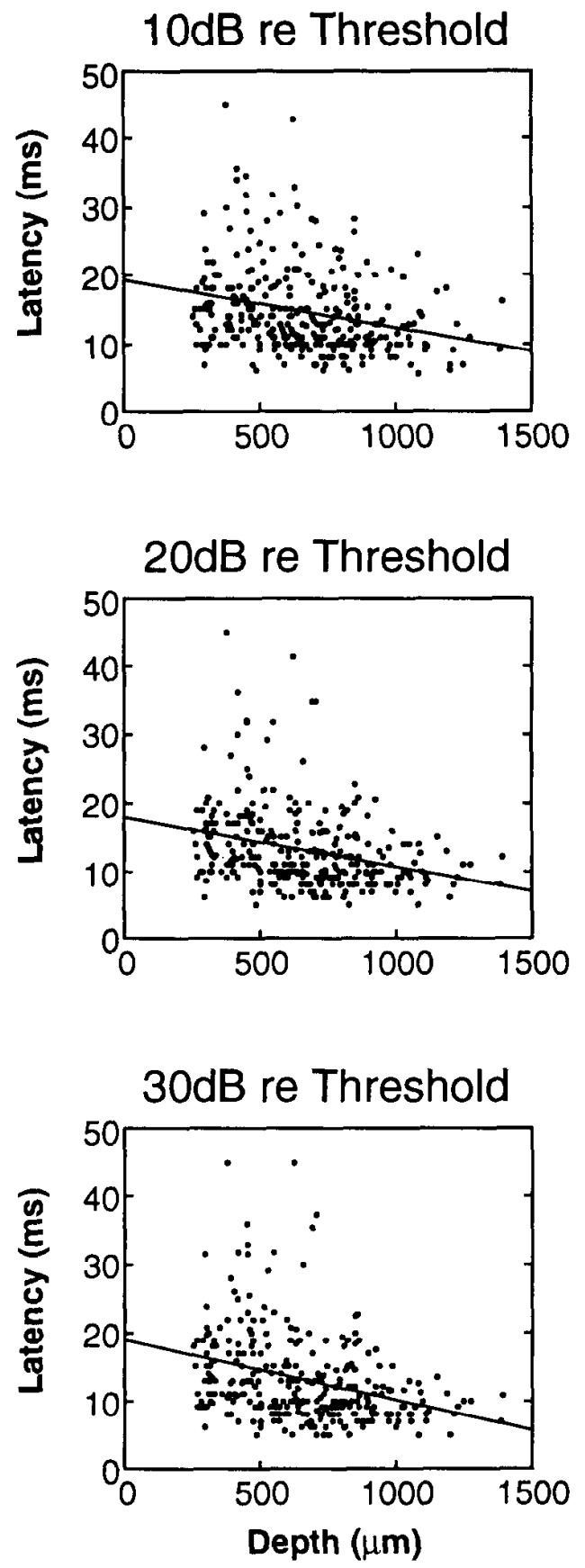

Figure 4. Latency plotted as a function of depth for 302 units at three intensities. 
A
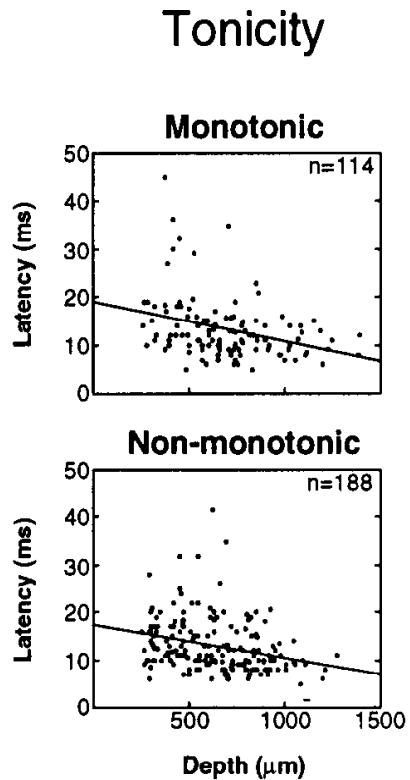

Resp. Pattern

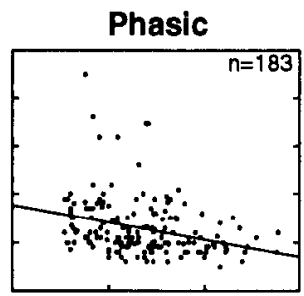

Sustained

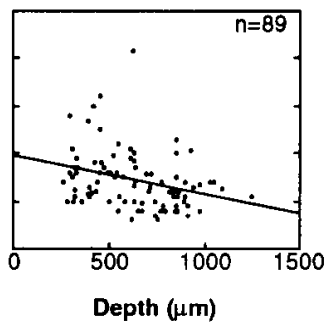

Aurality

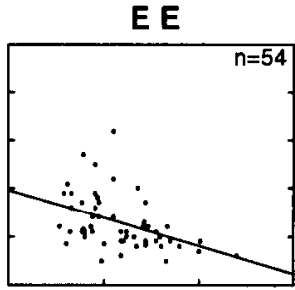

E 1

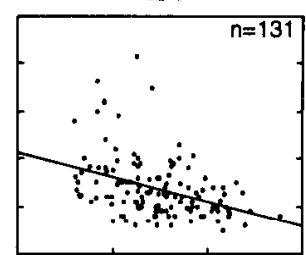

E O

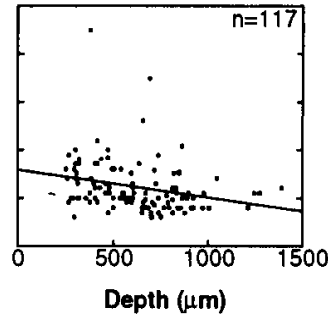

Figure 5. Plots of latency as as function of depth for cells with different response types. $A$, Distributions for cells with monotonic and nonmonotonic rate-intensity functions. $B$, Distributions for cells with phasic and sustained response patterns. $C$, Distributions for cells with different binaural and monaural properties.

functions was similar. To illustrate the latency pattern within

neurons that responded to tone bursts with a phasic discharge pattern (Fig. 5B).

Both phasic and sustained units, as well as units that had monotonic and nonmonotonic rate-intensity functions, were found at all dorsoventral levels of the EI, EE, and EO regions. In each of the aural subregions, the latency pattern observed for neurons with the different discharge patterns and rate-intensity an aural subregion, Figure 6 (top) shows four EI neurons recorded at different depths. Both of the phasic and sustained cells in Figure 6, $A$ and $B$, were recorded from the dorsal EI subregion, and both had long latencies, whereas the phasic and sustained cells in Figure 6, $C$ and $D$, were recorded from the ventral EI subregion and had short latencies.

\section{Dorsal}

A

Figure 6. PST histograms of four EI units from different dorsoventral locations and with different discharge patterns. For each unit, the top graph shows responses prior to bicuculline application and the bottom graph shows responses with bicuculline. Numbers below the graphs are the median latency to first spike in milliseconds and the depth of the unit (distance from the dorsal surface) in micrometers. $A$, Phasic cell from the dorsal region. This cell appears to have had an on-off response pattern with a weak on-component prior to bicuculline application; with bicuculline, the on-component was much more prominent. $B$, Sustained cell from the dorsal region. $C$, Phasic cell from the ventral region. $D$, Sustained cell from the ventral region.

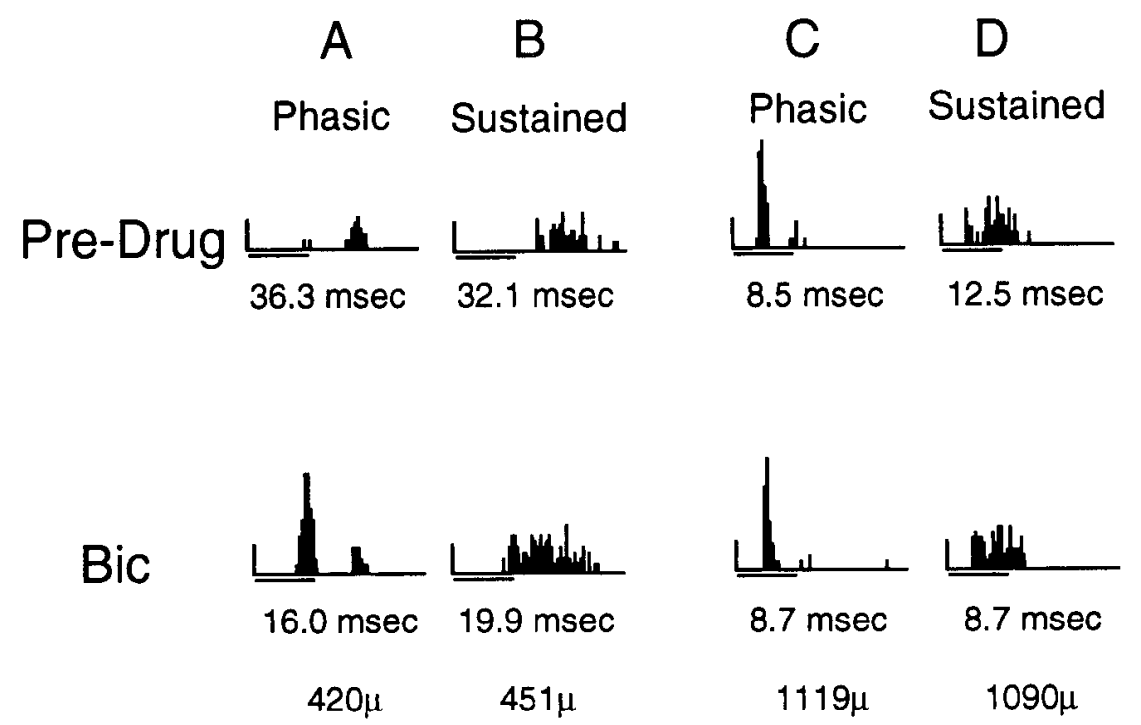


Table 2. Average latency and range for dorsal, intermediate, and ventral regions of the $60 \mathrm{kHz}$ contour for 302 cells

\begin{tabular}{|c|c|c|c|c|c|c|}
\hline \multirow[b]{2}{*}{$\begin{array}{l}\text { Intensity re } \\
\text { threshold }\end{array}$} & \multicolumn{3}{|l|}{ Population } & & & \\
\hline & $\begin{array}{l}\text { Dorsal } \\
(200-600 \\
\mu \mathrm{m}) \\
\end{array}$ & $\begin{array}{l}\text { Intermediate } \\
(600-1000 \\
\mu \mathrm{m}) \\
\end{array}$ & $\begin{array}{l}\text { Ventral } \\
(1000- \\
1400 \mu \mathrm{m}) \\
\end{array}$ & & & \\
\hline $10 \mathrm{~dB}$ & $16.4,39$ & $13.8,37$ & $11.6,17$ & & & \\
\hline $20 \mathrm{~dB}$ & $14.8,40$ & $12.0,37$ & $9.8,10$ & & & \\
\hline \multirow[t]{2}{*}{$30 \mathrm{~dB}$} & $15.2,40$ & $11.8,40$ & $8.8,9$ & & & \\
\hline & \multicolumn{3}{|l|}{ Monotonic } & \multicolumn{3}{|c|}{ Nonmonotonic } \\
\hline $\begin{array}{l}\text { Intensity re } \\
\text { threshold }\end{array}$ & $\begin{array}{l}\text { Dorsal } \\
(200-600 \\
\mu \mathrm{m}) \\
\end{array}$ & $\begin{array}{l}\text { Intermediate } \\
(600-1000 \\
\mu \mathrm{m})\end{array}$ & $\begin{array}{l}\text { Ventral } \\
(1000- \\
1400 \mu \mathrm{m})\end{array}$ & $\begin{array}{l}\text { Dorsal } \\
(200-600 \\
\mu \mathrm{m})\end{array}$ & $\begin{array}{l}\text { Intermediate } \\
(600-1000 \\
\mu \mathrm{m})\end{array}$ & $\begin{array}{l}\text { Ventral } \\
(1000- \\
1400 \mu \mathrm{m})\end{array}$ \\
\hline $10 \mathrm{~dB}$ & $18.1,39$ & $14.1,24$ & $12.5,17$ & $15.4,25$ & $13.6,36$ & $10.2,8$ \\
\hline $20 \mathrm{~dB}$ & $15.9,40$ & $11.9,30$ & $10.3,9$ & $14.2,26$ & $12.2,36$ & $9.0, \quad 9$ \\
\hline \multirow[t]{2}{*}{$30 \mathrm{~dB}$} & $15.8,40$ & $11.3,33$ & $9.2,9$ & $14.9,26$ & $12.1,40$ & $8.2,8$ \\
\hline & \multicolumn{3}{|l|}{ Phasic } & \multicolumn{3}{|l|}{ Sustained } \\
\hline $\begin{array}{l}\text { Intensity re } \\
\text { threshold }\end{array}$ & $\begin{array}{l}\text { Dorsal } \\
(200-600 \\
\mu \mathrm{m}) \\
\end{array}$ & $\begin{array}{l}\text { Intermediate } \\
(600-1000 \\
\mu \mathrm{m}) \\
\end{array}$ & $\begin{array}{l}\text { Ventral } \\
(1000- \\
1400 \mu \mathrm{m}) \\
\end{array}$ & $\begin{array}{l}\text { Dorsal } \\
(200-600 \\
\mu \mathrm{m}) \\
\end{array}$ & $\begin{array}{l}\text { Intermediate } \\
(600-1000 \\
\mu \mathrm{m}) \\
\end{array}$ & $\begin{array}{l}\text { Ventral } \\
(1000- \\
1400 \mu \mathrm{m})\end{array}$ \\
\hline $10 \mathrm{~dB}$ & $15.8,38$ & $13.4,22$ & $11.4,17$ & $18.4,25$ & $15.3,36$ & $13.6,13$ \\
\hline $20 \mathrm{~dB}$ & $14.4,39$ & $12.2,29$ & $9.3,10$ & $16.2,24$ & $12.9,36$ & $12.9,3$ \\
\hline \multirow[t]{2}{*}{$30 \mathrm{~dB}$} & $14.7,39$ & $12.0,33$ & $8.4,9$ & $16.3,29$ & $12.5,40$ & $11.5,3$ \\
\hline & \multicolumn{3}{|l|}{ EO } & \multicolumn{3}{|l|}{ EI } \\
\hline $\begin{array}{l}\text { Intensity re } \\
\text { threshold } \\
\end{array}$ & $\begin{array}{l}\text { Dorsal } \\
(200-600 \\
\mu \mathrm{m}) \\
\end{array}$ & $\begin{array}{l}\text { Intermediate } \\
(600-1000 \\
\mu \mathrm{m}) \\
\end{array}$ & $\begin{array}{l}\text { Ventral } \\
(1000- \\
1400 \mu \mathrm{m}) \\
\end{array}$ & $\begin{array}{l}\text { Dorsal } \\
(200-600 \\
\mu \mathrm{m}) \\
\end{array}$ & $\begin{array}{l}\text { Intermediate } \\
(600-1000 \\
\mu \mathrm{m}) \\
\end{array}$ & $\begin{array}{l}\text { Ventral } \\
(1000- \\
1400 \mu \mathrm{m})\end{array}$ \\
\hline $10 \mathrm{~dB}$ & $14.5,38$ & $12.1,17$ & $11.0,9$ & $19.0,28$ & $15.7,37$ & $12.3,17$ \\
\hline $20 \mathrm{~dB}$ & $13.5,39$ & $11.0,29$ & $10.7,6$ & $16.6,29$ & $13.3,36$ & $9.9,10$ \\
\hline \multirow[t]{2}{*}{$30 \mathrm{~dB}$} & $13.8,39$ & $10.9,31$ & $9.8,6$ & $17.1,30$ & $13.1,40$ & $8.9,9$ \\
\hline & \multicolumn{3}{|l|}{$\underline{\mathrm{EE}}$} & & & \\
\hline $\begin{array}{l}\text { Intensity re } \\
\text { threshold } \\
\end{array}$ & $\begin{array}{l}\text { Dorsal } \\
(200-600 \\
\mu \mathrm{m}) \\
\end{array}$ & $\begin{array}{l}\text { Intermediate } \\
(600-1000 \\
\mu \mathrm{m}) \\
\end{array}$ & $\begin{array}{l}\text { Ventral } \\
(1000- \\
1400 \mu \mathrm{m}) \\
\end{array}$ & & & \\
\hline $10 \mathrm{~dB}$ & $16.2,26$ & $11.7,14$ & $8.5,6$ & & & \\
\hline $20 \mathrm{~dB}$ & $14.8,27$ & $10.6,15$ & $7.3,3$ & & & \\
\hline $30 \mathrm{~dB}$ & $15.1,28$ & $9.6,15$ & $6.3,3$ & & & \\
\hline
\end{tabular}

Results are in milliseconds; numbers in parentheses are micrometers of depth from the dorsal surface of the colliculus. For each intensity and region of the colliculus the average latency for the units in that region is given, followed by the range.

\section{Effects of bicuculline on latency}

Latencies were determined before and during the application of bicuculline in 142 units. In $55 \%$ of the cells ( 79 of 142), bicuculline caused latency to shorten. In $41 \%$ of the cells ( 59 of 142 ), bicuculline had no effect on latency, and in 3\% of the cells $(4$ of 142), bicuculline caused latency to lengthen by $1-5 \mathrm{msec}$. Cells in which latency shortened with bicuculline were divided into cells whose latencies shortened by $1-5 \mathrm{msec}$ and cells whose latencies shortened by $5-25 \mathrm{msec}$. Latencies shortened by $1-5$ msec in $38 \%$ (54) of the units and by $5-25 \mathrm{msec}$ in $17 \%(25)$ of the neurons. Representative examples are shown in Figures 6 and 7.

The effects of bicuculline were reflected in the distribution of latencies for the 142 cells tested. Figure $8, A$ and $B$, shows the latency distributions at $20 \mathrm{~dB}$ above threshold before and during bicuculline application, respectively. We only show the effects of bicuculline for $20 \mathrm{~dB}$ above threshold, since the latency distributions obtained at 10,20 , and $30 \mathrm{~dB}$ above threshold were similar (Fig. 1), as were the latency changes induced by bicuculline (Table 3). For stimuli $20 \mathrm{~dB}$ above threshold, bicuculline caused the distribution to narrow considerably and most of the cells that had the longest latencies ( $>20 \mathrm{msec}$ ) prior to bicuculline, had substantially shorter latencies with bicuculline (Fig. $8 B$ ). As a consequence, the average latency of the population shortened from $14.3 \mathrm{msec}$ prior to bicuculline, to $11.8 \mathrm{msec}$ with bicuculline $(t-6.233, \mathrm{df}=141, p<0.01$, paired $t$ test $)$. 
Figure 7. Raster displays of three units showing different effects on latency from bicuculline. Only the first spike to each stimulus is shown. Responses were evoked by 20 tone bursts at characteristic frequency, $20 \mathrm{~dB}$ above threshold. There are three graphs for each unit. The top graph shows discharges evoked before bicuculline application, the middle graph shows discharges evoked with bicuculline, and the bottom graph is after a recovery period. $A$, Neuron whose latency was unaffected by bicuculline. $B$, Neuron that shortened latency moderately by about $4 \mathrm{msec}$ with bicuculline. $C$, Neuron whose latency was shortened by more than $20 \mathrm{msec}$ with bicuculline. This cell appears to have had an on-off response pattern but with no first spikes occurring in the on-component prior to bicuculline application and no first spikes occuring in the offcomponent with bicuculline.

\section{Mechanisms that produced bicuculline-induced latency changes}

Bicuculline caused latencies to shorten in two main ways. Each way caused 1-5 msec latency changes in some cells and larger changes in others. The first way was that when bicuculline was
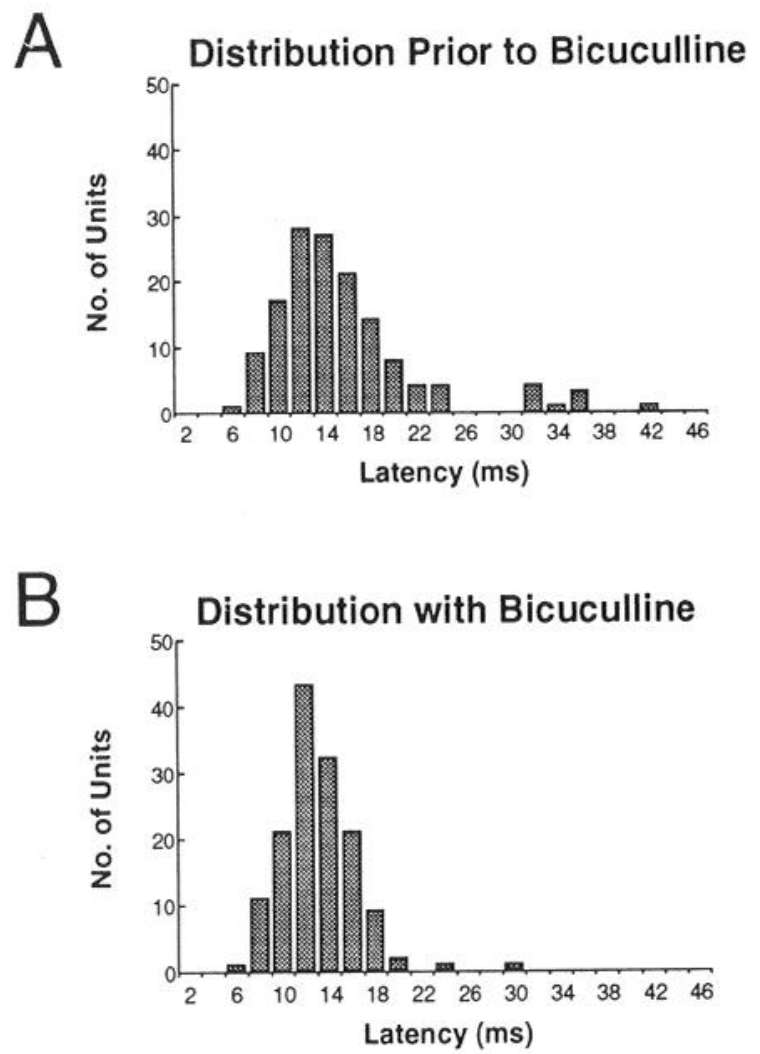

Figure 8. Effects of bicuculline on the distribution of latencies for 142 units. $A$, Histogram showing the distribution of latencies prior to the application of bicuculline. $B$, Distribution of latencies with bicuculline. The majority of cells shifted to shorter latencies with bicuculline. Note that the longest latencies in the predrug distribution became much shorter with bicuculline. Responses were evoked by 20 presentations of characteristic frequency tone bursts at $20 \mathrm{~dB}$ above threshold.

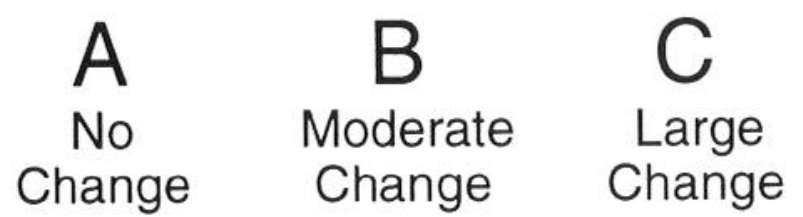

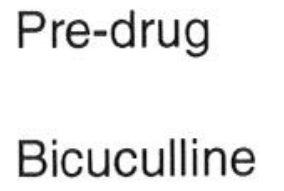

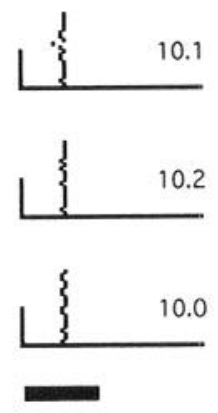

$20 \mathrm{msec}$
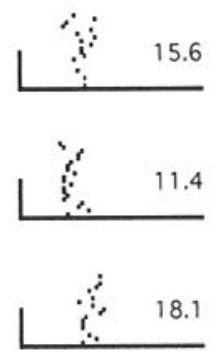
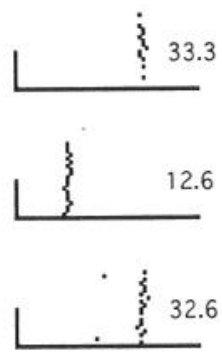

applied, tone bursts evoked discharges at shorter latencies than those at which the cell normally responded. In this way, latency was shortened in 53 of the 79 cells that changed $1-5$ msec with bicuculline and in 19 of the 25 neurons that had shifts greater than $5 \mathrm{msec}$ with bicuculline. An example of a $3 \mathrm{msec}$ latency shift with bicuculline is illustrated by the neuron in Figure $9 A$. Two neurons with larger latency shifts are shown in Figure 9, $B$ and $C$. For the neuron in Figure $9 B$, a sustained discharge pattern with a median latency of $32 \mathrm{msec}$ was evoked in the predrug condition. With bicuculline, the latency shortened by about $12.4 \mathrm{msec}$ due to the addition of discharges with shorter latencies. The unit in Figure $9 C$ responded to tone bursts in the predrug condition with long-latency discharges that appeared to be evoked by the offset of the signal. With bicuculline, vigorous onset responses in addition to offset responses were evoked, causing latency to shorten by $19.6 \mathrm{msec}$. A change in firing pattern from what appeared to be a response to the offset of the signal to an on-off response with bicuculline was seen in 4 of the 25 cells that showed a large reduction in latency with bicuculline. For this type of effect by bicuculline, the amount of latency change was directly linked to the duration of the signal.

The second way that bicuculline shortened latency was that it caused the latencies of the first spikes to become more synchronized in units that had relatively desynchronized latencies in the predrug condition. In other words, in the predrug condition cells fired with relatively short latencies to some stimulus presentations and with longer latencies to others. Bicuculline greatly increased the proportion of discharges with relatively short latencies, thereby producing a more synchronized first spike pattern. Enhanced synchronization was observed in 26 of the 79 cells that had latency shifts of $1-5 \mathrm{msec}$ and in 6 of the 25 neurons that had larger latency shifts. The unit in Figure 9D is an example of a unit whose latency shortened by less than 5 msec due to a greater synchronization of first spikes. The largest latency changes due to an enhanced bicuculline-induced synchronization were seen in six cells that had on-off discharge patterns in the predrug condition. An example is shown in Figure $9 E$. In these cells some of the first spikes occurred to the onset of the stimulus and others occurred to the offset of the stimulus. With bicuculline, these cells retained their on-off patterns but most, or in some cases all, of the first spikes occurred to the 
Table 3. Average latency of 142 cells before (Pre) and during bicuculline application (Bic) for the population and different response types at three intensities

\begin{tabular}{|c|c|c|c|c|c|c|c|c|c|c|}
\hline \multirow{2}{*}{$\begin{array}{l}\text { Intensity } \\
\text { re } \\
\text { threshold } \\
\end{array}$} & \multicolumn{2}{|c|}{$\begin{array}{l}\text { All cells } \\
(n=142)\end{array}$} & \multicolumn{2}{|c|}{$\begin{array}{l}\text { Monotonic } \\
(61)\end{array}$} & \multicolumn{2}{|c|}{$\begin{array}{l}\text { Nonmonotonic } \\
(81)\end{array}$} & \multicolumn{2}{|c|}{$\begin{array}{l}\text { Phasic } \\
\text { (113) }\end{array}$} & \multicolumn{2}{|c|}{$\begin{array}{l}\text { Sustained } \\
(29)\end{array}$} \\
\hline & Pre & Bic & Pre & Bic & Pre & Bic & Pre & Bic & Pre & Bic \\
\hline $10 \mathrm{~dB}$ & 16.4 & 14.7 & 16.8 & 14.9 & 16.1 & 14.4 & 15.3 & 13.9 & 20.6 & 17.4 \\
\hline $20 \mathrm{~dB}$ & 14.3 & 11.8 & 14.4 & 11.9 & 14.1 & 11.8 & 13.5 & 11.5 & 17.2 & 13.1 \\
\hline $30 \mathrm{~dB}$ & 14.0 & 12.2 & 14.0 & 11.7 & 14.7 & 12.1 & 13.5 & 11.5 & 17.8 & 13.5 \\
\hline $\begin{array}{l}\text { Intensity } \\
\text { re }\end{array}$ & $\begin{array}{l}\text { EO } \\
(31) \\
\end{array}$ & & $\begin{array}{l}\text { EI } \\
(99) \\
\end{array}$ & & $\begin{array}{l}\mathrm{EE} \\
(12) \\
\end{array}$ & & & & & \\
\hline threshold & Pre & Bic & Pre & $\mathrm{Bic}$ & Pre & Bic & & & & \\
\hline $10 \mathrm{~dB}$ & 14.8 & 13.7 & 17.1 & 15.1 & 14.0 & 12.9 & & & & \\
\hline $20 \mathrm{~dB}$ & 13.9 & 11.8 & 14.4 & 12.0 & 14.0 & 10.4 & & & & \\
\hline $30 \mathrm{~dB}$ & 14.8 & 12.1 & 14.3 & 11.7 & 14.3 & 12.7 & & & & \\
\hline
\end{tabular}

Results are in milliseconds; numbers in parentheses are number of units.

onset of the stimulus, thereby causing the median latency to shorten by a large degree. Another way of viewing this effect is that bicuculline caused a change in the proportion of responses to the onset of the stimulus for these six cells.

Some cells in which latency shortened substantially exhibited both effects. However, in those cells the effect of inhibiting the earliest spikes far outweighed the contribution of the enhanced synchronization (e.g., Fig. 9B).
Bicuculline effects on the latencies of units with different response features.

The synchronization of initial discharges was much more pronounced in sustained cells than in phasic neurons. The reason is that sustained cells were more desynchronized prior to bicuculline than the phasic cells. Thus, the average latency of the sustained cells at $20 \mathrm{~dB}$ above threshold was $17.2 \mathrm{msec}$ in the predrug condition and shortened to $13.1 \mathrm{msec}$ with bicuculline,

\section{A \\ B \\ C

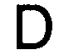 \\ $E$}
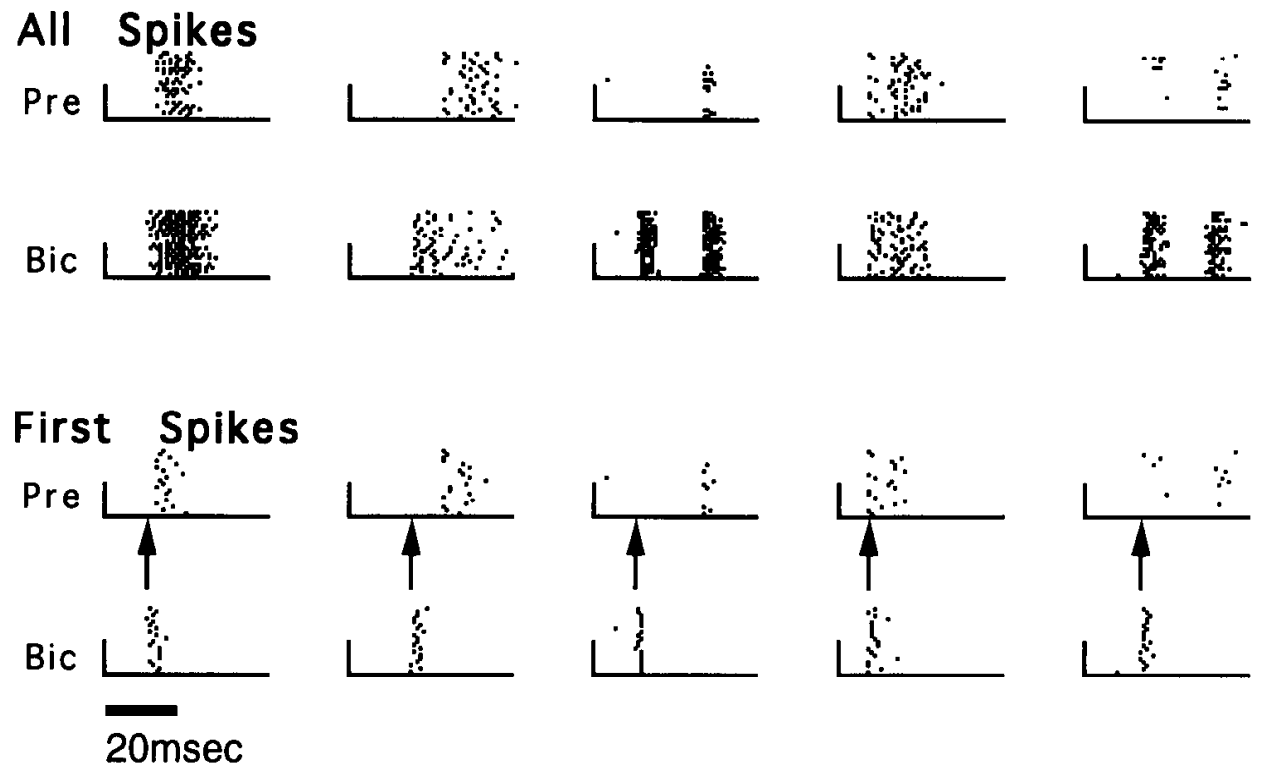

$20 \mathrm{msec}$

Figure 9. PST histograms of four cells illustrating the ways in which bicuculline shortened latency. Responses were evoked by 20 presentations of a tone burst at characteristic frequency, $20 \mathrm{~dB}$ above threshold. Four graphs are shown for each cell. The top graph shows all the spikes evoked by 20 stimulus repetitions in the predrug condition (Pre). The second graph shows all spikes evoked by the same stimuli with bicuculline (Bic). The $t$ wo lower graphs show only the first spike to each stimulus presentation. The arrows indicate the shortest response time with bicuculline. $A$, Neuron in which bicuculline caused the addition of early discharges that were not evoked in the predrug condition. $B$, Neuron showing both the appearance of earlier spikes and an increased synchronization of first spikes with bicuculline. $C$, Neuron with an offset firing pattern in the predrug condition that changed to an on-off pattern with bicuculline. (Note that the predrug response may have been a long-latency onset response and not an offset response. This seems unlikely, however, since bicuculline shortened the latency by approximately the same duration as the stimulus) $D$, Neuron whose first spikes became more synchronized with bicuculline. $E$, On-off neuron that remained on-off with bicuculline but whose first spikes became synchronized in the onset component. [A response pattern was considered to be on-off if the interval between the two responses was the same as the duration of the stimulus ( 20 msec).] 
A
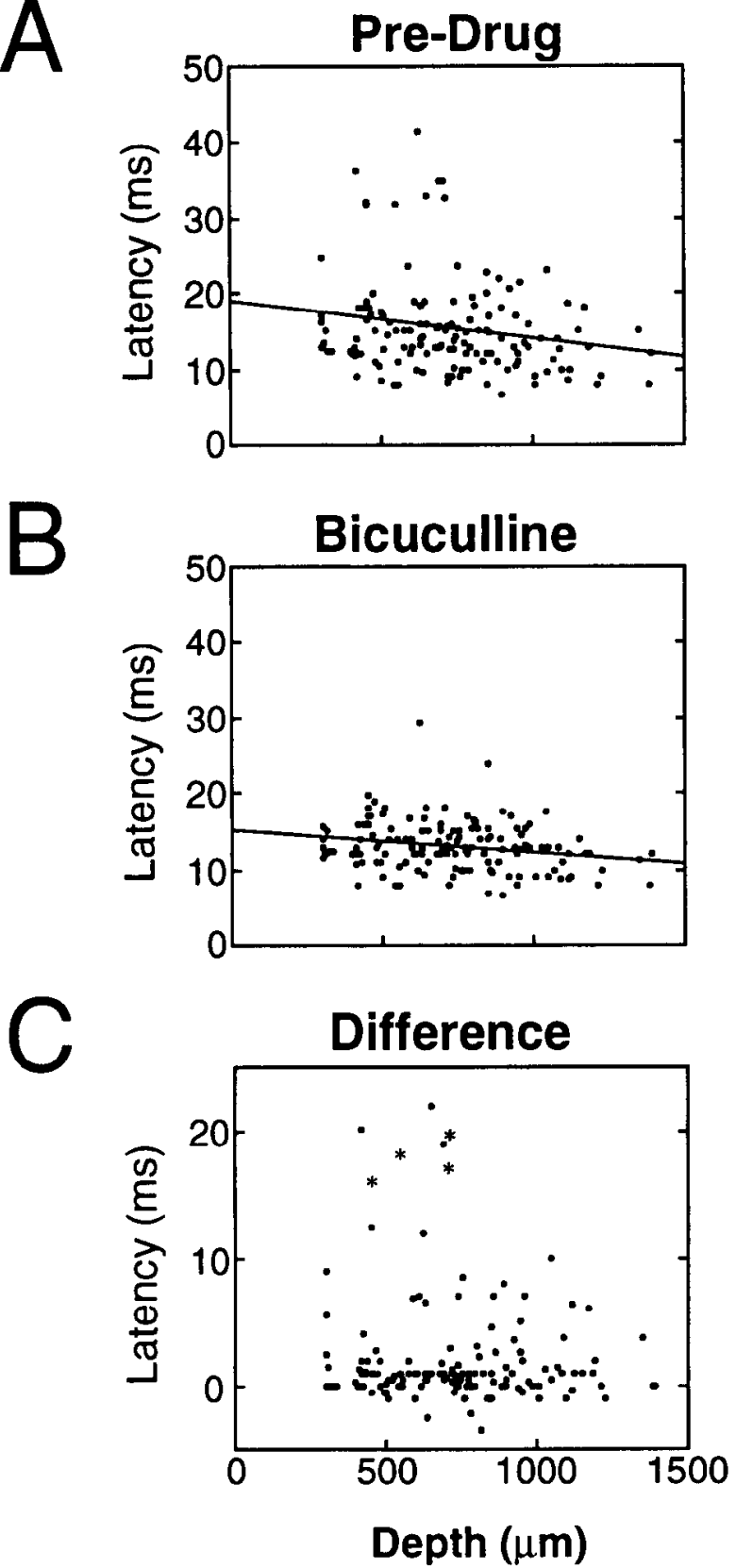

Figure 10. Effects of bicuculline on the pattern of latency with depth for 142 cells. $A$, Plot of latency as a function of depth prior to bicuculline application. $B$, Latencies of the same cells during bicuculline application. $C$, Graph showing the difference in latency for each unit from bicuculline as a function of depth. The four asterisks indicate the units whose response patterns changed from offset to on-off with bicuculline.

a change of $4.1 \mathrm{msec}$. In contrast, during the application of bicuculline the average latency of the phasic cells shortened from 14.4 to $11.9 \mathrm{msec}$, a change of only $2.5 \mathrm{msec}$. Examples of the way in which bicuculline affected the latencies of a sustained and a phasic cell are shown in Figure 3. The entire spike train, as well as first spikes, are shown for the predrug condition on the left and with bicuculline on the right. The phasic cell in Figure $3 A$ had relatively well synchronized first spikes that became only slightly more synchronized with bicuculline. In contrast, the first spikes of the sustained cell in Figure $3 B$ became much more synchronized with bicuculline compared to the predrug condition. This is particularly apparent at 20 and 30 $\mathrm{dB}$ above threshold.
Although bicuculline shortened the latencies of sustained units to a greater degree than phasic units, it did not have differential effects on the latencies of units with different rate-intensity functions or aural preferences (Table 3).

\section{Effects of bicuculline on the pattern of latency with depth}

One of the important findings of this study is that the majority of neurons that had large $(>5 \mathrm{msec})$ changes in latency with bicuculline were located in the dorsal regions of the inferior colliculus. Very few neurons in the more ventral regions of the inferior colliculus had large bicuculline-induced latency changes, although some of those neurons had latencies of 15-20 msec and thus could have shortened substantially. These features are illustrated by the three graphs in Figure 10. Figure $10 \mathrm{~A}$ shows the distribution of latencies as a function of depth for the 142 units at $20 \mathrm{~dB}$ above threshold before bicuculline was applied. The pattern resembles the pattern of the entire sample in Figure 4 , in that neurons with the longest latencies were located dorsally, while neurons located more ventrally had, on the average, shorter latencies and a less variable latency range. The graph in Figure $10 B$ shows the latency distribution during the application of bicuculline. The most apparent feature is the absence of neurons in the dorsal inferior colliculus, between 200 and $600 \mu \mathrm{m}$ from the surface, that had latencies longer than $20 \mathrm{msec}$ during the application of bicuculline. There was also a reduction in the range of latencies at more ventral levels. At levels between 600 and $1000 \mu \mathrm{m}$ there was a smaller number of neurons with long latencies than in the predrug graph, although two neurons still had latencies above $20 \mathrm{msec}$. In the most ventral inferior colliculus, at depths of 1000-1400 $\mu \mathrm{m}$, there was a reduction in the range of latencies, but the overall latency change due to bicuculline was smaller than in the more dorsal regions.

The difference between the latency before and during the application of bicuculline for neurons at the various levels of the inferior colliculus is plotted graphically in Figure $10 \mathrm{C}$. Here the largest changes in latency are clearly apparent for the neurons in the dorsal regions of the inferior colliculus, while the neuronal population located ventrally had the smallest latency change. The latency range and average latency at each level are shown for the predrug and bicuculline conditions in Table 4, and examples of bicuculline effects on the latencies of dorsal and ventral cells are shown in Figure 6. It is also noteworthy that the latencies of large numbers of neurons at all levels of the inferior colliculus were not changed by bicuculline.

\section{Discussion}

The experiments reported here describe several aspects of response latency in an isofrequency contour of the inferior colliculus and how blocking GABA affects latency. The latencies of collicular neurons tuned to $60 \mathrm{kHz}$ ranged from 5 to $45 \mathrm{msec}$ and the majority were clustered between 8 and $20 \mathrm{msec}$. The cells displayed a characteristic pattern of latency changes with depth at 10, 20, and $30 \mathrm{~dB}$ above threshold. The same pattern was observed for cells that had different aural preferences, different rate-intensity functions, and different discharge patterns. Blocking GABAergic inhibition with bicuculline substantially shortened latency in about half of the cells studied and it dramatically changed the latency pattern with depth. Below we first compare our data with those from previous studies and discuss the implications of the topographical latency pattern and other response features for a general view of the organizational features of the inferior colliculus. We then discuss the delay mechanisms and the circuits that could generate those mechanisms. 
Table 4. The average latency and range for dorsal, intermediate, and ventral regions of the $60 \mathrm{kHz}$ contour in both the predrug (Pre) and bicuculline (Bic) conditions

\begin{tabular}{|c|c|c|c|c|c|c|}
\hline \multirow{2}{*}{$\begin{array}{l}\text { Intensity } \\
\text { re } \\
\text { threshold }\end{array}$} & \multicolumn{2}{|c|}{ Dorsal $(200-600 \mu \mathrm{m})$} & \multicolumn{2}{|c|}{$\begin{array}{l}\text { Intermediate } \\
(600-1000 \mu \mathrm{m})\end{array}$} & \multicolumn{2}{|c|}{ Ventral $(1000-1400 \mu \mathrm{m})$} \\
\hline & Pre & $\mathrm{Bic}$ & Pre & Bic & Pre & Bic \\
\hline $10 \mathrm{~dB}$ & $17.4,30$ & $15.0,19$ & $16.3,36$ & $14.8,30$ & $14.1,17$ & $13.2,16$ \\
\hline $20 \mathrm{~dB}$ & $15.0,28$ & $12.4,12$ & $14.6,35$ & $12.1,23$ & $11.3,15$ & $9.6,6$ \\
\hline $30 \mathrm{~dB}$ & $15.9,29$ & $13.0,25$ & $14.4,39$ & $12.1,29$ & $11.2,25$ & $8.9,6$ \\
\hline
\end{tabular}

Results are in milliseconds; numbers in parentheses are micrometers of depth from the dorsal surface of the colliculus. For each intensity and region of the colliculus the average latency for the units in that region is given, followed by the range.

Finally, we discuss how collicular cells with different latencies may contribute to the formation of combination sensitive neurons in the medial geniculate body.

\section{Comparisons with previous studies}

The distribution of latencies in the $60 \mathrm{kHz}$ contour of the mustache bat inferior colliculus is similar to the latency distributions of inferior colliculus cells that have been reported previously, except for one study. The exception is a recent study by $\mathrm{Ku}$ wabara and Suga (1993). They recorded the latencies of fibers in the brachium of the inferior colliculus in the mustache bat and report that the fibers tuned to $60 \mathrm{kHz}$ had very short latencies that ranged from 3.5 to $6 \mathrm{msec}$. The vast majority of 60 $\mathrm{kHz}$ fibers had latencies around $4 \mathrm{msec}$ and none had latencies greater than $7 \mathrm{msec}$ at any intensity. These results differ markedly from ours and the reasons for these differences are unclear.

On the other hand, the range of latencies that we found in the $60 \mathrm{kHz}$ contour agrees closely with those found in more common laboratory animals (gerbil, Semple and Kitzes, 1985; cat, Schreiner and Langner, 1988; Irvine and Gago, 1990) as well as other bats (Bodenhamer and Pollak, 1981; Jen and Schlegel, 1982; Jen and Suthers, 1982). The latencies of collicular neurons in these animals vary widely, but the majority of latencies tend to cluster between about 5 and $15 \mathrm{msec}$. The concordance among these values is remarkable given the differences in brain size among these animals and that the latencies were obtained at different intensities and from different criteria. In addition, the longer latencies of sustained compared to phasic neurons that we observed in the mustache bat were seen in collicular neurons of other mammals (Ryan and Miller, 1978; Kuwada et al., 1984; Irvine, 1986). Finally, a topographic arrangement of latencies within frequency contours has also been found by Schreiner and Langner (1988) in the cat inferior colliculus. Although they recorded latencies evoked by stimulation at $60 \mathrm{~dB}$ above threshold for characteristic frequency tones, whereas we recorded latencies at lower intensities, the results of the two studies are complementary. Their data, together with ours, suggest that an orderly arrangement of latencies within frequency contours is a general organizational feature of the inferior colliculus.

Schreiner and Langner (1988) also proposed that the arrangement of other functional properties may be embedded within aural subregions of frequency contours. They reported that optimal responses evoked by amplitude-modulated signals having different modulation rates are topographically arranged in frequency contours of the cat's inferior colliculus. Furthermore, they suggested that an orderly arrangement of sensitivity to amplitude-modulated rates may be represented within each au- ral subregion of a frequency contour. While we did not employ sinusoidally amplitude-modulated signals, our results concerning the distribution of latencies within aural subregions are consistent with their hypothesis.

\section{Various levels of organization exist within a frequency contour}

The results of this study also provide insights into the increasingly finer levels of organization in the inferior colliculus. Previous studies have shown that the dominant organizational feature of the inferior colliculus is its division into frequency contours (Merzenich and Reid, 1974; FitzPatrick, 1975; Roth et al., 1978; Bodenhamer and Pollak, 1981; Zook et al., 1985; Aitkin, 1986; Irvine, 1986; Pollak and Casseday, 1989). Within each contour, there are regions dominated by monaural or one of the two types of binaural neurons (Roth et al., 1978; Wenstrup et al., 1985, 1986; Schreiner and Langner, 1988), which we refer to as aural subregions. The results presented here also show that sustained and phasic neurons with either monotonic or nonmonotonic rate-intensity functions occur throughout each of the aural subregions of the $60 \mathrm{kHz}$ contour. Thus, at any dorsoventral level of an aural subregion in the $60 \mathrm{kHz}$ contour, populations of neurons will be present that have phasic and sustained discharge patterns as well as neurons that have monotonic and nonmonotonic rate-intensity functions. Other features are arranged orthogonal to the dorsoventral axis and change quantitatively along this spatial dimension. One of these features is latency range, as shown in the present study. Another may be sensitivity for amplitude modulation rate, as shown by Schreiner and Langner (1988) in the cat. Finally, in the case of EI neurons there is also an orderly change with depth of the interaural intensity disparity that causes the discharge rate to decline by $50 \%$ (Wenstrup et al., 1985, 1986).

\section{GABAergic inhibition lengthens the latencies of many neurons}

Our results indicate that one way by which GABAergic inhibition lengthens the latency of many collicular neurons is by suppressing initial discharges. The simplest explanation for this effect is that these collicular cells receive both a GABAergic and an excitatory innervation, where the GABAergic inhibition is stronger than the excitation. Assuming that both inputs reach the collicular cell simultaneously, or nearly so, and that the excitatory discharge train is longer than the inhibitory discharge train, then the latency of the collicular cell is lengthened by a delay equal to the period during which the two inputs overlap. The period of overlap, in turn, can differ from cell to cell. For example, the period can be lengthened if the duration of the inhibitory discharge train is long. On the other hand, the period can be shortened if the inhibitory discharge train is short, or if 
it arrives slightly earlier than the excitatory input. In these ways, GABAergic inhibition can produce a wide range of latencies in the population of collicular cells. Blocking the GABAergic inputs with bicuculline shortens latency by allowing the collicular cell to respond to the excitatory input earlier than the cell did when the GABAergic inputs were active.

A second way that GABA lengthens latencies is to cause a desynchronization of the initial discharges. This effect was most pronounced in sustained cells. The explanation for this effect requires a different set of conditions than those proposed for the suppression of the initial discharges of the train. When GABAergic inhibition was blocked by bicuculline, not only did the discharge rate of many sustained cells increase markedly throughout the entire duration of the spike train, but in addition, the initial spikes fell into tight registration. These features suggest that in the absence of inhibition, the excitatory inputs caused a rapid rise of the membrane potential of the target cell and the membrane potential remained depolarized throughout the duration of the stimulus. Thus, the membrane potential may have reached threshold at about the same time with each stimulus presentation, resulting in a fairly constant initial discharge latency followed by a high, sustained discharge rate. The GABAergic inhibition in these cells, like the excitatory inputs, must have been sustained but was not sufficiently strong to cancel the effects of the excitation completely. In this scenario the net result would be that in the presence of GABAergic inhibition, the rise time of the membrane potential lengthens and its magnitude is reduced. Together these changes could produce a marked variation in the time at which the cell reached threshold after receiving the excitatory inputs, where successive stimulus presentations sometimes evoked a faster rise time and larger depolarization than was evoked by the same stimulus at other times. These variations would be reflected both in the desynchronization of the initial spikes and in the marked reduction of discharge rate.

\section{Possible sources of the GABAergic inhibition that shortens latencies of collicular neurons}

GABAergic innervation of the inferior colliculus originates from a variety of sources. These include projection neurons from this ipsilateral intermediate nucleus of the lateral lemniscus (Vater et al., 1992; Winer et al., 1993), bilateral projections from the dorsal nuclei of the lateral lemniscus (Adams and Mugniani, 1984; Mugniani and Ortel, 1985; Thompson et al., 1985; Roberts and Riback, 1987a,b; Oliver et al., 1988; Schneiderman et al., 1988; Ross et al., 1989; Schneiderman and Oliver, 1989; Pollak and Winer, 1989; Glendenning et al., 1992; Pollak et al., 1992; Vater et al., 1992), and intrinsic collicular neurons (Adams and Wenthold, 1979; Mugniani and Ortel, 1985; Thompson et al., 1985; Moore and Moore, 1987; Roberts and Riback, 1987a,b; Oliver et al., 1988; Pollak and Winer, 1989; Caspary et al., 1990; Vater et al., 1992; Winer et al., 1993). The intrinsic neurons may be either interneurons that act only locally or principal neurons that provide collaterals to their neighbors en route to their targets in higher-order nuclei, such as the medial geniculate body (Oliver et al., 1991; Saldana and Merchan, 1992).

One of the significant aspects of GABAergic innervation of the mustache bat inferior colliculus is the distribution of GABAergic puncta. There is a pronounced gradient in the density of the GABAergic innervation of collicular cells, where GABAergic puncta are most abundant dorsally and become progressively sparser ventrally (Winer et al., 1993). There is, then, a striking correlation between the regional density of GABAergic innervation and the degree to which latencies shortened in the dorsal compared to the ventral inferior colliculus when GABAergic inhibition was blocked by bicuculline. However, the issue of whether the gradient of GABAergic inhibition is due to differential projections from local interneurons, or from projection neurons, or from a combination of both, is unclear.

\section{Orderly arrangement of latencies has implications for the creation of combination-sensitive neurons in the medial geniculate body}

As discussed previously, the orderly arrangement of response properties seems to be a general feature of collicular frequency contours. If this is correct, then a neuron's location within a contour could specify its response properties. The topographic arrangement of response features may have special significance for the mustache bat because of the remarkable response properties that are generated in the medial and dorsal divisions of the medial geniculate body by the convergence of projections from at least two frequency contours (Olsen and Suga, 1991a,b; Buttman, 1992). The convergence results in the emergence of combination-sensitive neurons in the medial geniculate, a feature that is not present in the inferior colliculus (O'Neill, 1985). If the organization of response properties in the other frequency contours is comparable to those reported here for the $60 \mathrm{kHz}$ contour, as we have argued they are, then all of the response features required to generate combinatorial properties are already established and arranged by locus in the various frequency contours of the inferior colliculus. These considerations lead us to suggest that the appropriate combinatorial properties could be created by the convergence of projections from a given locus in one frequency contour and the projections from a different locus in another frequency contour. Below, we present two hypothetical circuits that could generate the combinatorial properties in medial geniculate body neurons. The circuits are based on the assumption that there is an orderly arrangement of latencies in all of the collicular frequency contours.

The circuits are applicable to the two general types of combination-sensitive neurons that have been found in the mustache bat's medial geniculate body. One type, the so-called CF/ CF neurons, is characterized by weak discharges to a single tone burst and vigorous firing when two tone bursts having different frequencies are presented together (Olsen and Suga, 1991a). These neurons are also distinguished by their relative insensitivity to the temporal interval separating the presentation of the two frequencies. The other type, called delay-tuned neurons, is also most effectively driven by two tone bursts (or FM chirps) that have different frequencies, but in addition, requires that the two tone bursts be presented in a specific temporal order (Olsen and Suga, 1991b). The delay-tuned properties are a consequence of the latency differential with which the inputs evoked by each of the two frequencies arrive at the neuron in the medial geniculate body. Below, we first propose a circuit for the generation of $\mathrm{CF}$ ' CF neurons and then suggest a slightly different circuitry that could lead to the formation of delay-tuned neurons.

The circuit for CF/CF neurons must account for the facilitated response from two specific frequencies and for the finding that the facilitation can be evoked over a wide range of temporal intervals separating the two tone bursts. To construct the appropriate circuit, we visualize first that a large number of 60 $\mathrm{kHz}$ cells project to a common neuron in the medial geniculate. Furthermore, the projections arise from a dorsoventral column 
of cells in the contour (Fig. 11, top). Thus, the medial geniculate body cell receives projections from a population of $60 \mathrm{kHz}$ collicular cells where each cell has a different latency. We next add projections from a population of topographically ordered cells in the $30 \mathrm{kHz}$ contour, which then would also provide a wide distribution of latencies. The net result of this arrangement is that the presentation of a $30 \mathrm{kHz}$ and a $60 \mathrm{kHz}$ tone would evoke activity from the two frequency contours, and that the excitation evoked in the medial geniculate body neuron by the convergence of inputs from the two contours would be independent of the interval separating the two tones. If, for instance, the $30 \mathrm{kHz}$ tone was presented 10 msec prior to the $60 \mathrm{kHz}$ tone, the $30 \mathrm{kHz}$ tone would evoke a response in the medial geniculate body cell over a wide range of intervals, since each projection neuron would be activated sequentially. The $60 \mathrm{kHz}$ tone, arriving $10 \mathrm{msec}$ later, would also evoke activity distributed over time. The important feature is that since the populations of both the $30 \mathrm{kHz}$ and $60 \mathrm{kHz}$ cells have distributed latencies, the discharges from at least some of the $30 \mathrm{kHz}$ neurons will arrive simultaneously with the discharges from some $60 \mathrm{kHz}$ cells and thereby evoke a facilitated response. Since the latency distributions of both the 30 and $60 \mathrm{kHz}$ projection cells are presumably large, there will be a convergence of excitation from some cells of both frequencies regardless of the time interval separating the two signals.

The projections from the two frequency contours that could generate delay-tuned neurons must be somewhat different (Fig. 11 , bottom). The circuit has to satisfy the additional criterion that the facilitated response occur only when there is a particular interval between the two signals (Olsen and Suga, 1991b). Such properties could be achieved if projections from a region of the $30 \mathrm{kHz}$ contour, where latencies are long, converged with the projections from the ventral $60 \mathrm{kHz}$ contour, where latencies are relatively short. Under these conditions, the two tones presented simultaneously would arrive at their targets in the medial geniculate at different times, and elicit a small response. However, if the $60 \mathrm{kHz}$ signal was delayed relative to the $30 \mathrm{kHz}$ signal by an interval equal to the latency differential evoked by the two frequencies, then the two inputs should converge simultaneously on the cell in the medial geniculate body, resulting in a facilitated discharge.

An arrangement of the sort described above can be extended and thereby account for two additional features of delay-tuned neurons. The first feature is the distribution of delay-tuned values. One way this could be achieved would be if a $60 \mathrm{kHz}$ cell, having a particular latency, sent projections to several medial geniculate body cells (Fig. 11, bottom). These medial geniculate cells would also receive innervation from a population of topographically ordered $30 \mathrm{kHz}$ cells, where the locus of each 30 $\mathrm{kHz}$ cell defined its latency. Each $30 \mathrm{kHz}$ cell, however, would project to only one medial geniculate cell. Thus every medial geniculate cell in this array would be innervated with a common latency by the $60 \mathrm{kHz}$ cell, but any given medial geniculate cell would be innervated with a different latency by the particular $30 \mathrm{kHz}$ cell that projects to it. An arrangement of this sort would create a population of cells, each endowed with a different delaytuned value (Fig. 11, bottom). Another dividend derived from this arrangement is that it provides a simplified mechanism for generating a map of delay-tuning. The ordered projection system described above would at once generate a diversity of delaytuned values and an orderly change in the delay-tuned values among the population of target cells in the medial geniculate

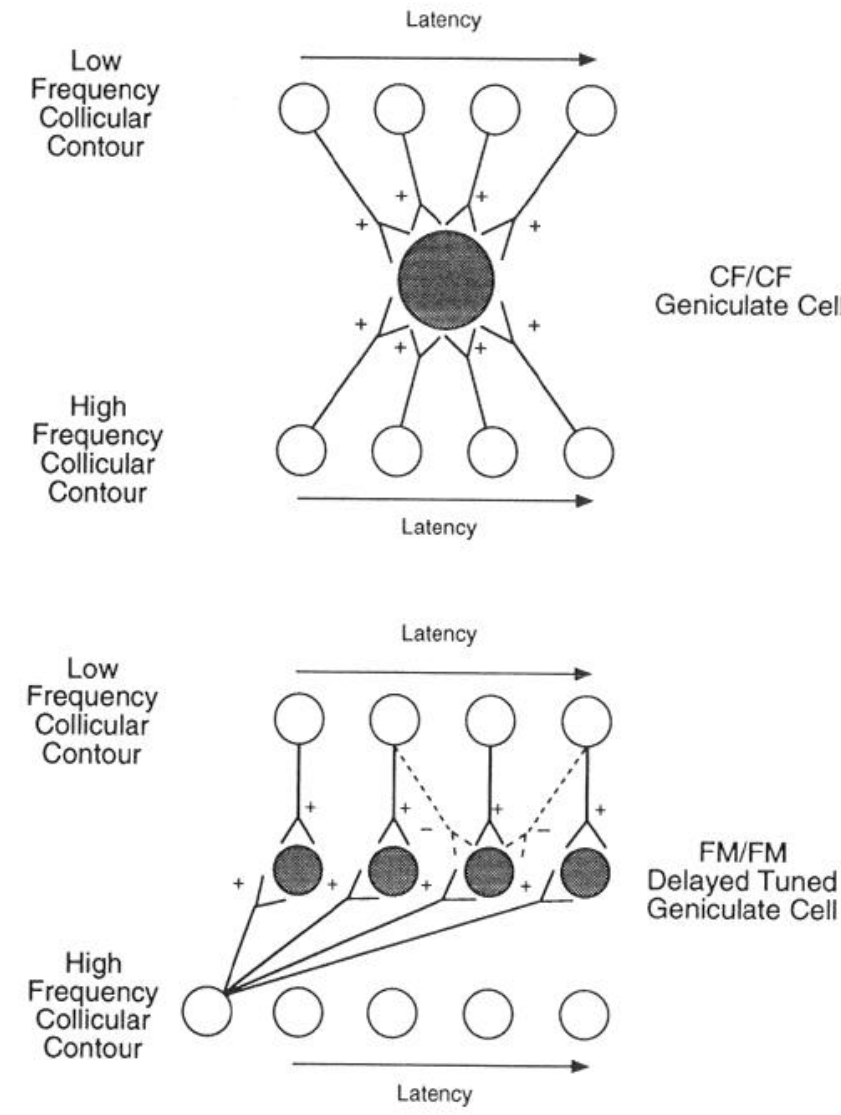

Figure 11. Top, Hypothetical circuit showing inputs from two isofrequency contours that could generate porperties appropriate for $\mathrm{CF} / \mathrm{CF}$ neurons in the forebrain. Bottom, Hypothetical circuit showing inputs to an FM/FM neuron. See text for discussion.

body (Olsen and Suga, 1991b). Assuming an orderly arrangement of latencies in other frequency contours, we point out that this way of creating delay-tuned neurons can be generalized to any combination of two frequencies and does not have to include $60 \mathrm{kHz}$ cells. Moreover, the converging projections from any two collicular contours can be mixed and matched to create delay-tuned neurons in some cases, $\mathrm{CF} / \mathrm{CF}$ neurons in others, and perhaps properties that are currently unknown in yet others.

The second feature that requires explanation concerns the difference between neurons tuned to short best delays and those tuned to long best delays (Olsen and Suga, 1991b; Buttman, 1992). Medial geniculate neurons tuned to short delays are coincidence detectors and are thought to be generated only by the convergence of two excitatory inputs. Medial geniculate neurons tuned to long delays, however, are more complex and are created by interactions of excitation and inhibition. In these neurons, delays shorter or longer than the optimal delay inhibit the cell. Thus, the delay value to which the unit is tuned is sandwiched between periods of inhibition. The circuitry we proposed for generating delay-tuned neurons can easily incorporate inhibitory as well as excitatory projections (Fig. 11, bottom). The mustache bat inferior colliculus contains a large population of GABAergic principal neurons (Pollak and Winer, 1989; Pollak et al., 1992; Vater et al., 1992; Winer et al., 1993), which presumably provide inhibitory inputs to the medial geniculate body. One can postulate, for example, three topographically arranged projections from the $30 \mathrm{kHz}$ contour; the first is an inhibitory 
projection with a short latency, the second is an excitatory projection with a slightly longer latency, and the third is another inhibitory projection with a latency somewhat longer than the second. The latency of the second neuron could generate an excitatory coincidence with the $60 \mathrm{kHz}$ projection at a particular delay that would be sandwiched between the inhibitory periods produced by the shortest and longest latencies of the $30 \mathrm{kHz}$ projections, thereby sharpening the neuron's delay tuning. These features satisfy many of the properties seen in long delay neurons in the medial geniculate body by Olsen and Suga (1991a).

An issue that has not previously been raised is that a mismatch in the aural properties of the convergent projections could confound the latency specificity of the delay-tuned projection system. The reason is that if the projection from one of the frequency contours were monaural and the projection from the other frequency were binaural, then interactions from the two ears could change the latency of the binaural projection. Latency changes due to binaural interactions can be up to $4 \mathrm{msec}$ in the mustache bat inferior colliculus (Park and Pollak, unpublished observations). If this occurred, then the delay-tuning of a given medial geniculate neuron would also vary with the interaural intensity disparity, and hence with location of the sound source in space. The finding that the population of neurons in each of the $60 \mathrm{kHz}$ aural subregions expresses a similar latency ordering seems significant in this regard. If a comparable arrangement exists in each of the other frequency contours, then a combinatorial projection system segregated according to aural type could be readily achieved. In such an arrangement, monaural projection neurons from the two frequency contours would converge on a common medial geniculate cell and similarly for the binaural types. If this proves to be correct, it would simplify what otherwise would appear to be a seriously confounded system.

In conclusion, the results indicate that the full range of delays, as well as other response properties required to form combinatorial neurons are present in the inferior colliculus and that the delays are arranged with a characteristic pattern in at least one frequency contour. We have also proposed a simplified model by which the convergence of projections from two frequency contours of the colliculus could, theoretically, generate the properties of the various types of combinatorial neurons in the medial geniculate body. Whether or not the combinatorial properties are, in fact, created by such convergences remains for future studies to determine.

\section{References}

Adams JC, Mugniani E (1984) Dorsal nucleus of the lateral lemniscus: a nucleus of GABAergic projection neurons. Brain Res Bull 13:585590.

Adams JC, Wenthold RJ (1979) Distribution of putative amino acid transmitters, choline acetyltransferase and glutamate decarboxylase in the inferior colliculus. J Neurosci 4:1947-1951.

Aitkin LM (1986) The auditory midbrain: structure and function in the central auditory pathway. Clifton, NJ: Humana.

Bodenhamer RD, Pollak GD (1981) Time and frequency domain processing in the inferior colliculus of echolocating bats. Hearing Res 5:317-335.

Borman J (1988) Electrophysiology of $\mathrm{GABA}_{A}$ and $\mathrm{GABA}_{B}$ receptor subtypes. Trends Neurosci 11:112-116.

Brugge JF, Dubrovsky NA, Aitkin LM, Anderson DJ (1969) Sensitivity of single neurons in auditory cortex of the cat to binaural tonal stimulation: effects of varying time and intensity. J Neurophysiol 32: $1005-1024$.

Buttman JA (1992) Inhibitory and excitatory mechanisms of coinci- dence detection in delay tuned neurons of the mustache bat. Proc Third Internat Cong Neuroethol, p 34.

Caird D, Klinke R (1983) Processing of binaural simuli by cat superior olivary neurons. Exp Brain Res 52:385-399.

Carr CE, Konishi M (1988) Axonal delay lines for time measurement in the owl's brainstem. Proc Natl Acad Sci USA 85:8311-8315.

Carr CE, Konishi M (1990) A circuit for detection of interaural time differences in the brain stem of the barn owl. J Neurosci 10:32273246.

Caspary DM, Raza A, Lawhorn-Armour BA, Pippen J, Arneric SP (1990) Immunocytochemical and neurochemical evidence for age related loss of GABA in inferior colliculus: implications for neural presbycusis. J Neurosci 10:2363-2372.

Cooper JR, Bloom FE, Roth R (1982) The biochemical basis of neuropharmacology. New York: Oxford UP.

FitzPatrick KA (1975) Cellular architecture and topographic organization of the inferior colliculus of the squirrel monkey. J Comp Neurol 164:185-208.

Glendenning KK, Baker BN, Hutson KA, Masterton RB (1992) Acoustic chiasm $\mathrm{V}$ : inhibition and excitation in the ipsilateral and contralateral projections of LSO. J Comp Neurol 319:100-122.

Goldberg JM, Brown PB (1969) Response of binaural neurons of dog superior olivary complex to dichotic tonal stimuli: some physiological mechanisms of sound localization. J Neurophysiol 32:613-636.

Hattori T, Suga N (1989) Latency map in the inferior colliculus of the mustached bat. Abstr Assoc Res Otolaryngol 12:94.

Havey DC, Caspary DM (1980) A simple technique for contructing "piggy back" multibarrel microelectrodes. Electroencephalogr Clin Neurophysiol 48:249-251.

Irvine DRF (1986) The auditory brainstem. In: Progress in sensory physiology, Vol 7 (Autrum H, Ottoson D, eds). Berlin: Springer.

Irvine DRF, Gago G (1990) Binaural interaction in high-frequency neurons in inferior colliculus of the cat: effects of variations in sound pressure level on sensitivity to interaural intensity differences. J Neurophysiol 63:570-591.

Jeffress LA (1948) A place theory of sound localization. J Comp Physiol Psychol 41:35-39.

Jen PH-S, Schlegel PA (1982) Auditory physiological properties of the neurons in the inferior colliculus of the big brown bat, Eptesicus fuscus. J Comp Physiol 147:351-363.

Jen PH-S, Suthers RA (1982) Responses of inferior colliculus neurons to acoustic stimuli in certain FM and CF-FM paleotropical bats. J Comp Physiol 146:423-434.

Kuwabara N, Suga N (1988) Mechanisms for the production of "rangetuned" neurons in the mustached bat: delay lines and amplitude selectivity are created in the auditory midbrain nuclei. Abstr Assoc Res Otolaryngol 11:200.

Kuwabara N, Suga N (1993) Delay lines and amplitude selectivity are created in subthalamic auditory nuclei: the brachium of the inferior colliculus of the mustache bat. J Neurophysiol 69:1713-1724.

Kuwada S, Yin TCT, Syka J, Buunen TJF, Wickesberg RE (1984) Binaural interaction in low-frequency neurons in the inferior colliculus of the cat. IV. Comparison of monaural and binaural response properties. J Neurophysiol 51:1306-1325.

Merzenich MM, Reid MD (1974) Representation of the cochlea within the inferior colliculus of the cat. Brain Res 77:397-415.

Moore JK, Moore RY (1987) Glutamic acid decarboxylase-like immunoreactivity in brainstem auditory nuclei of the rat. J Comp Neurol 260:157-174.

Mugniani E, Oertel WH (1985) An atlas of the distribution of GABAergic neurons and terminals in rat CNS as revealed by GAD immunocytochemistry. In: Handbook of chemical neuroanatomy, Vol 4, GABA and neuropeptides in the CNS. Pt I (Bjorklund A, Hokfelt T, eds), pp 436-608. Amsterdam: Elsevier.

Oliver DL, Nuding SC, Beckius G (1988) Multiple cell types have GABA immunoreactivity in the inferior colliculus of the cat. Soc Neurosci Abstr 14:490.

Oliver DL, Kuwada S, Y in TCT, Haberly LB, Henkel CK (1991) Dendrtic and axonal morphology of HRP-injected neurons in the inferior colliculus of the cat. J Comp Neurol 303:75-100.

Olsen JF, Suga N (1991a) Combination-sensitive neurons in the medial geniculate body of the mustached bat: encoding relative velocity information. $J$ Neurophysiol 65:1254-1274.

Olsen JF, Suga N (1991b) Combination-sensitive neurons in the medial geniculate body of the mustached bat: encoding target range information. J Neurophysiol 65:1275-1296. 
O'Neill WE (1985) Responses to pure tones and linear FM components of the CF-FM biosonar signal by single units in the inferior colliculus of the mustached bat. J Comp Physiol 157:797-815.

O'Neill WE, Suga N (1982) Encoding of target-range information and its representation in the auditory cortex of the mustached bat. J Neurosci 47:225-255.

Overholt EM, Rubel EW, Hyson RL (1992) A circuit for coding interaural time differences in the chick brainstem. J Neurosci 12:16981708.

Park TJ, Pollak GD (1993) GABA shapes sensitivity to interaural intensity disparities in the mustache bat's inferior colliculus: implications for encoding sound location. J Neurosci 13:2050-2067.

Parks TN, Rubel EW (1975) Organization and development of brain stem auditory nuclei of the chicken: organization of projections from n. magnocellularis to n. laminaris. J Comp Neurol 164:435-448.

Pollak GD (1988) Time is traded for intensity in the bat's auditory system. Hearing Res $36: 107-124$.

Pollak GD, Casseday JH (1989) The neural basis of echolocation in bats. Berlin: Springer.

Pollak GD, Park TJ (1993) The effects of GABAergic inhibition on monaural response properties of neurons in the mustache bat's inferior colliculus. Hearing Res 65:99-117.

Pollak GD, Winer JA (1989) Glycinergic and GABAergic auditory brainstem neurons and axons in the mustache bat. Soc Neurosci Abstr $15: 1115$.

Pollak GD, Park TJ, Larue DT, Winer JA (1992) The role inhibitory circuits play in shaping receptive fields of neurons in the mustache bat's inferior colliculus. In: Principles of design and function in nervous systems (Singh RN, ed), pp 271-290. New Delhi: Wiley Eastern.

Purves RD (1981) Microelectrode methods for intracellular recording and iontophoresis. New York: Academic.

Roberts RC, Ribak CE (1987a) GABAergic neurons and axon terminals in the brainstem auditory nuclei of the gerbil. J Comp Neurol 258:267-280.

Roberts RC, Ribak CE (1987b) An electron microscopic study of GABAergic neurons and terminals in the central nucleus of the inferior colliculus. J Neurocytol 16:333-345.

Ross LS, Pollak GD (1989) Differential projections to aural regions in the $60 \mathrm{kHz}$ isofrequency contour of the mustache bat's inferior colliculus. J Neurosci 9:2819-2834.

Ross LS, Pollak GD, Zook JM (1988) Origin of ascending projections to an isofrequency region of the mustache bat's inferior colliculus. J Comp Neurol 270:488-505.

Roth GL, Aitkin LM, Andersen RA, Merzenich MM (1978) Some features of the spatial organization of the central nucleus of the inferior colliculus of the cat. J Comp Neurol 182:661-680.

Ryan A, Miller J (1978) Single unit responses in the inferior colliculus of the awake and performing rhesus monkey. Exp Brain Res 32:389407.

Saldana E, Merchan MA (1992) Intrinsic and commissural connections of the rat inferior colliculus. J Comp Neurol 319:417-437.

Schreiner CE, Langner G (1988) Periodicity coding in the inferior colliculus of the cat. II. Topographic organization. J Neurophysiol 60:1823-1840.

Schuller G, Radtke-Schuller S, Betz M (1986) A stereotaxic method for small animals using experimentally determined reference profiles. J Neurosci Methods 18:339-350.
Semple MN, Kitzes LM (1985) Single-unit responses in the inferior colliculus: different consequences of contralateral and ipsilateral auditory stimulation. J Neurophysiol 53:1467-1482.

Shneiderman A, Oliver DL (1989) EM autoradiographic study of the projections from the dorsal nucleus of the lateral lemniscus: a possible source of inhibitory inputs to the inferior colliculus. J Comp Neurol $286: 28-47$.

Shneiderman A, Oliver DL, Henkel CK (1988) The connections of the dorsal nucleus of the lateral lemniscus. An inhibitory parallel pathway in the ascending auditory system? J Comp Neurol 276:188208.

Suga N (1990) Cortical computation maps for auditory imaging. Neural Networks 3:3-21.

Suga N, O'Neill WE (1979) Neural axis representing target range in the auditory cortex of the mustached bat. Science 206:351-353.

Sullivan WE III (1982a) Neural representation of target distance in auditory cortex of the echolocating bat, Myotis lucifugus. J Neurophysiol 48:1011-1032.

Sullivan WE III (1982b) Possible neural mechanisms of target distance coding in auditory system of the echolocating bat, Myotis lucifugus. J Neurophysiol 48:1033-1047.

Sullivan WE III, Konishi M (1986) Neural map of interaural phase difference in the owl's brainstem. Proc Natl Acad Sci USA 83:84008404.

Thompson GC, Cortez AM, Lam DM-KK (1985) Localization of GABA immunoreactivity in the auditory brainstem of guinea pigs. Brain Res 339:1 19-122.

Vater M, Kössl M, Horn AKE (1992) GAD- and GABA-immunoreactivity in the ascending auditory pathway of horseshoe and mustache bats. J Comp Neurol 325:183-206.

Wenstrup JJ, Ross LS, Pollak GD (1985) A functional organization of binaural responses in the inferior colliculus. Hearing Res 17:191195.

Wenstrup JJ, Ross LS, Pollak GD (1986) Binaural response organization within a frequency-band representation of the inferior colliculus: implications for sound localization. J Neurosci 6:962-973.

Wenstrup JJ, Fuzessery ZM, Pollak GD (1988) Binaural neurons in the mustache bat's inferior colliculus: II. Determinants of spatial responses among $60 \mathrm{kHz}$ E-I units. J Neurophysiol 60:1384-1404.

Winer JA, Larue DT, Pollak GD (1993) GABA and glycine in the central auditory system of the mustache bat: structural substrates for inhibitory neuronal organization. J Comp Neurol, submitted.

Wong D, Maekawa M, Tanaka H (1992) The effect of pulse repetition rate on the delay sensitivity of neurons in the auditory cortex of the FM bat, Myotis lucifugus. J Comp Physiol [A] 170:393-402.

Yin TCT, Chan JCK (1990) Interaural time sensitivity in medial superior olive of rat. J Neurophysiol 64:465-488.

Yin TCT, Hirsch JA, Chan JCK (1985) Responses of neurons in the cat's superior colliculus to acoustic stimuli. II. A model of interaural intensity sensitivity. J. Neurophysiol 53:746-758.

Young SR, Rubel EW (1983) Frequency-specific projections of individual neurons in chick brain stem auditory nuclei. J Neurosci 3:13731378.

Zook JM, Winer JA, Pollak GD, Bodenhamer RD (1985) Topology of the central nucleus of the mustache bat's inferior colliculus: correlation of single unit properties and neuronal architecture. J Comp Neurol 231:530-546. 